\title{
Decision-Aiding Transit-Tracker Methodology for Bus Scheduling Using Real Time Information to Ameliorate Traffic Congestion in the Kathmandu Valley of Nepal
}

\author{
Keshav Bhattarai ${ }^{*}$, Mahmoud Yousef ${ }^{2}$, Alice Greife ${ }^{3}$, Sunil Lama ${ }^{4}$ \\ ${ }^{1}$ School of Geoscience, Physics, and Safety Science, University of Central Missouri, Warrensburg, USA \\ ${ }^{2}$ School of Computer Science and Mathematics, University of Central Missouri, Warrensburg, USA \\ ${ }^{3}$ College of Health, Science and Technology, University of Central Missouri, Warrensburg, USA \\ ${ }^{4}$ School of Computer Science and Mathematics, University of Central Missouri, Warrensburg, USA \\ Email: ‘bhattarai@ucmo.edu
}

How to cite this paper: Bhattarai, K., Yousef, M., Greife, A. and Lama, S. (2019) Decision-Aiding Transit-Tracker Methodology for Bus Scheduling Using Real Time Information to Ameliorate Traffic Congestion in the Kathmandu Valley of Nepal. Journal of Geographic Information System, 11, 239-291.

https://doi.org/10.4236/jgis.2019.112016

Received: April 10, 2019

Accepted: April 26, 2019

Published: April 29, 2019

Copyright $\odot 2019$ by author(s) and Scientific Research Publishing Inc. This work is licensed under the Creative Commons Attribution International License (CC BY 4.0).

http://creativecommons.org/licenses/by/4.0/ (c) (i) Open Access

\begin{abstract}
The bustling urban environment of Kathmandu Valley is characterized by unprecedented traffic congestion. Due to its bowel-shaped geography, gusty winds rarely remove vehicular emissions from the urban atmosphere, making Kathmandu one of Asia's most polluted cities, $100^{\text {th }}$ city in global pollution index. Over 500,000 vehicles travel daily on over $1600 \mathrm{~km}$ of roads covering over $675 \mathrm{sq} \cdot \mathrm{km}$ urban area. Thousands of low occupancy vehicles are added each year to the urban public transit system (UPTS). Kathmandu faces worse and unreliable traffic from the current UPTS mostly with low occupancy vehicles. Around 4.5 million urban denizens, both permanent and transient residents, suffer from unreliable UPTS. Traffic rules and daily transportation schedules are rarely followed, resulting in frequent traffic jams and accidents. Once experienced, visitors try avoiding the UPTS. Tourism, annually contributing almost 8 percent to Nepal's total annual GDP, also suffers from poor UPTS. Planners, policy makers, and politicians (P-actors) are seeking ways to improve sustainable UPTS to ameliorate stresses to family life and working hours for the urban majority. Aiming to help P-actors, we propose a transit-tracker model that uses real time information (RTI) in mobile phones and web-embedded devices to inform travelers, drivers, government authorities, and sub-admins. We argue that unreliability in the UPTS motivates urban elites to add more low occupancy vehicles, which in turn reduces already shrunken urban spaces and contributes more per capita air pollution than multi-occupancy vehicles. Since mobile and smart phones are capable of processing RTI to generate meaningful information and inform various
\end{abstract}


stakeholders in communicable languages, we argue that replacing low occupancy vehicles with multi-occupancy buses within a Bus Rapid Transit (BRT) system, on main roads with fixed schedules and strict traffic rules, would not only improve UPTS, but also reduce pollution in the Kathmandu Valley.

\section{Keywords}

Urban Public Transportation System (UPTS), P-Actors, Sustainability, Disaster, Pollution, Accident, Bus Rapid Transit (BRT)

\section{Introduction}

Planners, policy makers, and politicians (P-actors) have been struggling to efficiently manage the urban public transit system (UPTS) in a rapidly urbanizing environment. There are many challenges to sustain the quality of life in urban environments (QoLUE), where almost each day new complex structures are added to the already crowded urban spaces. Complex infrastructures and increasing population in urban areas have necessitated different modes of transit. Transportation plays a vital role in any urban space, and it offers an opportunity to $\mathrm{P}$-actors to demonstrate their performances in a concentrated area within a short time period. However, maintaining quality transportation with the least amount of road congestion has been an ongoing problem because of the addition of infrastructure and different types of vehicles each day to meet the needs of a growing population. Without proper transportation, urban denizens face imbalances between their work and domestic life, especially, because the transportation becomes unreliable and expensive [1], and adds an excessive amount of pollutants from older vehicles using leaded petroleum products.

Reliable transportation services have become a great concern in the Kathmandu Valley of Nepal (Figure 1) despite the operation of over 500,000 vehicles of various capacities. Kathmandu Valley faces an unprecedented level of traffic congestion, frequent vehicular accidents, and an increasingly unreliable public transit system.

The Kathmandu Valley is polluted from various sources. These include, but are not limited to, dust particles emitted from construction work and fine dust fumes from the clayey soils deposited on roads after each rain that get crushed into very fine pieces by hundreds of vehicles traveling over $1600 \mathrm{~km}$ of roads within the Greater Kathmandu City. Emissions from old-fashioned industries without electrostatic precipitators, and emissions from old vehicles using leaded petroleum products also contribute to pollution. Additionally, black carbon containing fumes originating from the cremation sites also adds to the atmospheric pollution. Urban denizens are finding it very difficult to inhale ambient air without using respirators (masks). After having experienced Kathmandu's pollution, visitors may become frustrated and be less likely to visit Kathmandu in the near future. This would hurt the tourism economy that contributes almost 


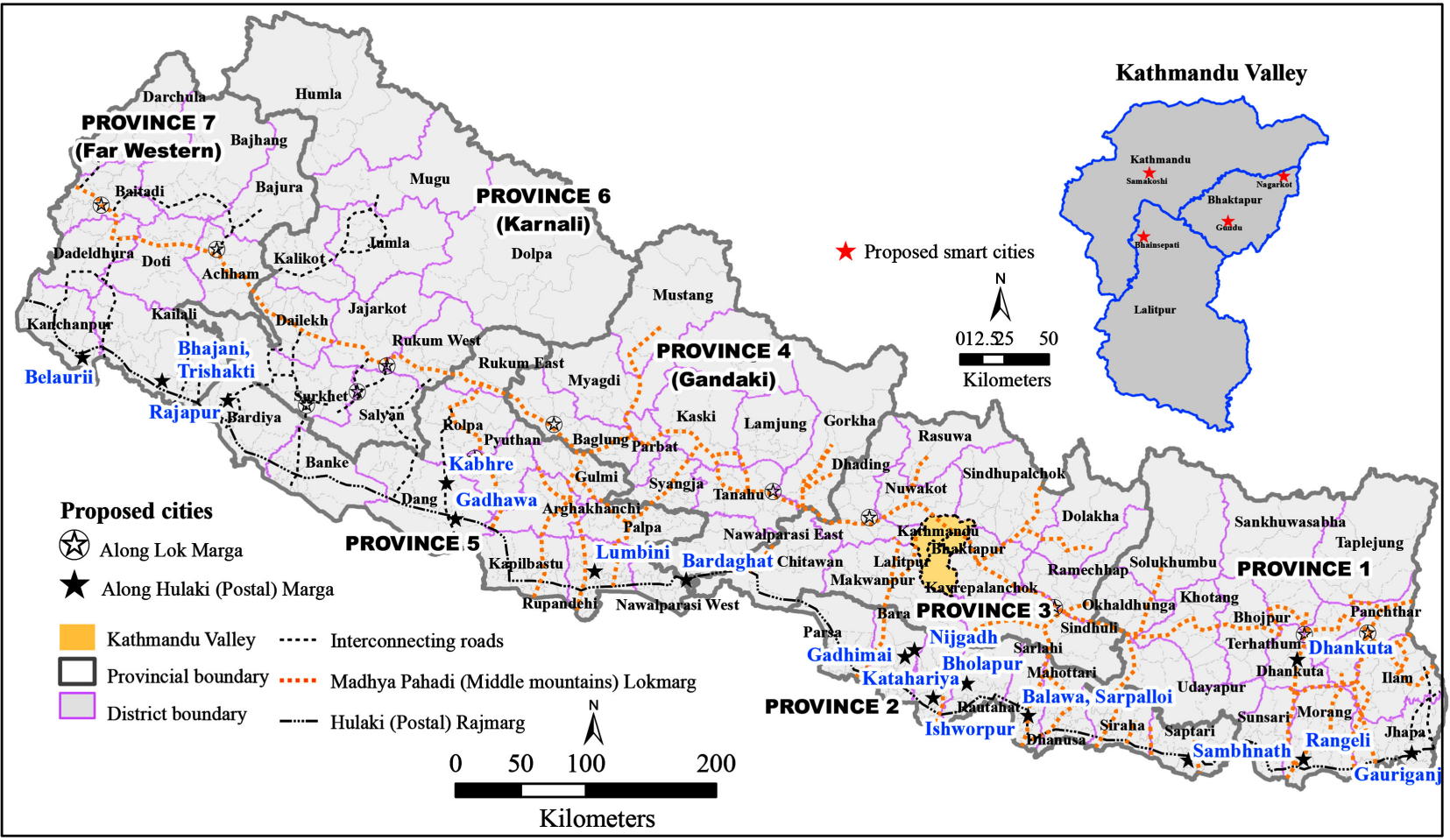

Figure 1. Urbanizing Nepal-showing the Kathmandu Valley in the set map.

7.57 percent ( $\$ 1779$ million in the year of 2017) of the country's gross domestic products (GDP) [2]. Direct contribution from tourism includes the economic activity generated by "hotels, travel agents, airlines, passenger transportation services, restaurant and leisure industries [1] [3]".

Using a prototype Transit-tracker JavaScript (Appendix A), this paper explores a means of mitigating Kathmandu's traffic and pollution by using real-time information (RTI). The prototype Apps operate on mobile and web-embedded devices and use RTI at four levels. These include: 1) normal users-the riders traveling to multiple locations; 2) drivers; 3) administrator, government authority, issuing permissions for bus routes; and 4) sub-administration-to assist the administrator.

The main goal of this paper is to improve the urban transit system by using RTI as transportation plays a vital role in contributing to smart mobility and sustaining the quality of urban life. It takes a long time to travel even short distances in heavy traffic and congested road conditions. This situation creates imbalance between work and family life, increases the cost of public transport services [1] and affects the living conditions of the public. Public transit plays a critical role in many modern transportation systems in "various urban environments," such as cities and metropolitan areas, as well as in "educational institutions" like schools and universities [1] [2].

Safer and more affordable modes of public transportation are needed in cities [4] [5], especially, when every individual cannot afford to have a personal vehicle, such as the case in the Kathmandu Valley. Operating too many low occu- 
pancy old vehicles, without engine improvements (oxidation catalysts to lower hydrocarbon and carbon monoxide), would add nitrogen oxide emissions to the atmosphere. Diesel engines are much worse for the environment because they produce particulate matter as a byproduct. An integration of filtration processes is essential to mitigate the environment from the emissions of diesel operating engines; however, such engine vehicles are very expensive. Operating many low occupancy vehicles including few seater cars and motorcycles at lower temperatures releases many particulate materials that pollute the environment. For the Kathmandu Valley, public transit has been the only means for large mobility of low-income people. An improvement in the public transit system is essential to ameliorate the valley's air quality, ameliorate traffic congestions with the improvement in mobility (speed), decreasing gasoline consumption while relieving vehicular congestions and reducing accidents in the urban areas. Today, many transit agencies are competing to provide quality transportation services, but none have become effective in the Kathmandu Valley. Only very recently, the Government of Nepal (GoN) has planned to acquire 300 electric operated high occupancy buses to assist in the mass transit; however, the service of these electric services may face a snag because of the lack of the recharging facilities. In addition, other transit systems have become less effective at serving the large community. As these public transits are becoming ineffective, many single-occupancy vehicles are increasingly plying on the streets of the Kathmandu Valley. These single occupancy vehicles are contributing to a lot more air pollution than the multi-occupancy vehicles do while comparing the per capita pollution emission [6]. P-actors of the Kathmandu Valley in particular and all over Nepal in general have been struggling to provide timely services to people, especially, living in the urban areas. Such transit systems need to be cost-effective, fast, reliable, frequent, regular, and less polluting [7].

Our attempt in this paper is to assess the existing public transit situation of the Kathmandu Valley and suggest a new mode of public transit system hoping to improve the quality of urban life. Currently, the Kathmandu Valley faces serious transit problems-overpassing without signals, stopping in multiple places without any signage, and irregularity in services. Many low occupancy vehicles are added every year to meet the needs of the growing population. Rarely, does the existing transit system provide timely services. Instead, they contribute to emission and pollute the Kathmandu Valley. People are spending a large portion of their productive time and income in commuting. Despite spending much of their income and time on transportation, the public are not served well with reliable transportation services. We propose the use of Transit-Tracker prototype Apps that utilize RTI to locate vehicles, estimate time of arrival (ETA), and inform the public about the traffic situations in relations to the road conditions. Our goal is to help commuters, P-actors, and private entrepreneurs to improve the public transit services using RTI. In the recent years, RTI has become increasingly cost-effective in regulating the transit system [6] [8]. The rapid adoption 
and widespread use of mobile phones and smartphones has facilitated information dissemination, which would be helpful to a large number of public transit riders [9].

This paper answers which transit mode, would be effective to ameliorate traffic congestion and pollution while making the transit-system of the Kathmandu Valley the most dependable for the public. Our hypothesis is that replacing low occupancy with large occupancy vehicles, and a technological shift from the use of petroleum products to an electric system would significantly reduce the health cost in the Kathmandu Valley. Also, we argue that our proposed model would be replicable not only to different cities of Nepal, but also around the world having similar spatial, demographic, and socioeconomic conditions where the operation of mono-and-metro rail systems are difficult to implement.

With this introduction, we structured our paper as follows. First, we explain a theoretical framework of how a prototype mobile application would become possible to navigate public transport mode to efficiently manage travel time at the local, region, and global scales. Second, we briefly present the scenarios of the current transit system of the Kathmandu Valley, and explain how a new mode of transit system would help improve the urban life quality. Third, we present an algorithm and a methodology explaining how our prototype operates on RTI databases. Fourth, we explain the universal application of our proposed methodology to ameliorate traffic congestion in metropolises like the Kathmandu Valley. Fifth, we present how our proposed system would help to improve the environmental conditions of the Kathmandu Valley. The last part will be the concluding remarks, followed by references.

\section{Conceptual Framework}

Almost for a century, urban planners, economists, sociologists, and architects have advanced theories on overall functioning of various urban areas. Some have hypothesized that poorly managed neighborhoods would further worsen the urban environment. Economic theories of change at the city level often emphasize population density and level of education to predict urban neighborhood environment and future improvement. Sociologists emphasize locations and social networks to predict improvements in a city's appearance. Geographers look at spatial associations to see the wellbeing of cities and their denizens, while computer scientists and mathematicians look at every urban activity both from micro-and-macro levels, especially, through modeling techniques.

One of the major components of a city is the public transit system that affects the quality of urban life [6]. The Bus Rapid Transit (BRT) system has become popular in many urban places because it can:

1) operate in varied topographic conditions;

2) adjust in varied socioeconomic and demographic conditions;

3) operate quickly, incrementally, and economically and its capacity can be modified even for largest metropolitan areas; 
4) operate in a wide range of environments without requiring expensive road construction [10];

5) operate in a cost-effective manner in city streets in mixed traffic systems;

6) operate at a lower cost than a railway system; and

7) operate at high speeds and on high-occupancy vehicle (HOV) lanes or on general-purpose highways and streets covering a variety of urban and suburban environments [10].

Historically, the concept of BRT first started in Chicago, U.S.A., to serve the city population where a railway system was not immediately possible [11]. Between 1955 and 1959, the model was adopted in Washington D.C. [12]; in 1959, it was adopted in St. Louis [13]; and in 1970, it was adopted in Milwaukee [14]. The reasons for the expansion of BRT were due to lower capital costs, a possibility for greater coverage, being capable of serving low-and medium-density areas, and more readily adaptable to changing land-use and population patterns than the rail systems [10]. Additionally, it was able to meet corridor demands in almost all the cities where railway system was not feasible.

Earlier, BRT system barely used real-time information (RTI) because of the lack of advanced digital technology. The concept of RTI started with the evolution of digital technology when passengers started timing their departure from their origin to minimize their wait time at various stops or stations [6]. Since passengers spent less time waiting at stops or stations, passengers perceived that RTI helps them to increase their personal security particularly at night riding [15]. Ferris et al. (2010) [16] conducted a survey of web-based RTI users for the city of Seattle, Washington, and concluded that the use of RTI increased self-reported levels of personal security by 18 percent; these users remarked RTI made transit "somewhat safer" and another three percent expressed "much safer." [17] continued survey in the same city and received positive responses from over 32 percent of the web-based RTI users. The follow-up surveys in the city of Seattle, in the year 2009, by [16] and in 2012, and by [17] revealed that 92 percent of the web-based RTI users expressed being secured. Since then, the use of RTI has increased in designing almost all the urban transit systems around the globe.

Real Time Information (RTI) uses Geographic data (GD) to provide location-specific information. Any GD is linked to a specific location by the geographic coordinate system (latitude and longitude) [18], and this particular characteristic distinguishes them from other forms of data. The spatial characteristic of GD is based on the angular relationships (cross points) between latitude and longitude-what makes a point unique. Eratosthenes, a Greek Geographer, first presented the idea of having imaginary horizontal lines on the earth. The biggest circle was marked as the equator (radius 3963 miles - 6378 kilometers), which was assumed to forming a Great Circle around the earth that is equidistant from the North and South Poles. Then the Tropics of Cancer $\left(23.5^{\circ} \mathrm{N}\right.$, the northernmost position on the summer solstices) where the sun is directly overhead dur- 
ing the summer and the Tropic of Capricorn $\left(23.5^{\circ} \mathrm{S}\right.$, the southernmost positions in which the sun is directly overhead on the winter solstices) were marked. Later, astronomer and mathematician, Hipparchus (190 - 125 BC) proposed that a set of equally spaced east-west lines called parallels be drawn on maps. Mathematician, Hipparchus also added a set of north-south lines called meridians that are equally spaced at the equator, but converge at the North and South Poles. The lines running east and west and the lines running north and south cross each other at different points and help to locate an absolute point on the earth (Figure 2) based on their angular relationships [18].

The numerical range of latitude is from $0^{\circ}$ at the equator to $90^{\circ}$ at the poles, and is represented by $\mathrm{N}$ or (+) for north and $\mathrm{S}$ or (-) for south. In 1884, the International Meridian Conference defined the north-south axis passing through the Royal Observatory in Greenwich, a suburb of London, and called it the Greenwich Meridian or the Central Meridian. Assuming this as center, the earth was portioned $0^{\circ}$ to $180^{\circ}$ east from the Central or Prime Meridian and $0^{\circ}$ to $180^{\circ}$ west of the Central Meridian, thus, completing $360^{\circ}$ of the earth as a full circle. East longitudes are labeled E or (+) and West longitudes as W or (-). When the latitude and longitude are geometrically put together on the earth surface, they cross each other and form the geographic coordinate that helps pinpoint an object on the earth's surface based on their angular relationships. Following the oldest Babylonian sexagesimal system, the spacing of latitudes and longitudes are marked by degrees $\left({ }^{\circ}\right)$, minutes ('), and seconds (") or the decimal degree.

$$
\text { Degree Decimal }=\text { Degree }+\frac{\text { minute }}{60}+\frac{\text { second }}{3600}
$$

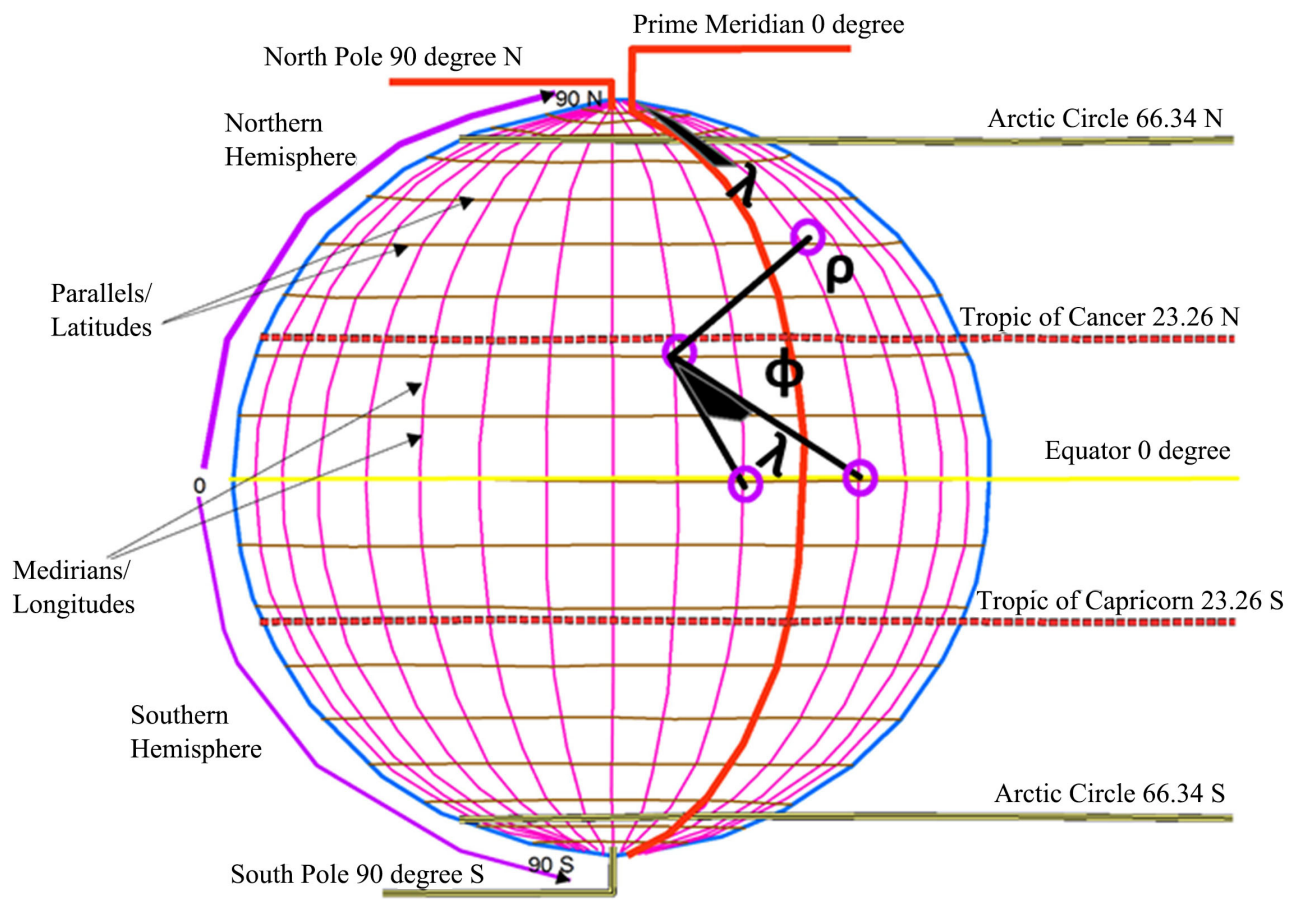

Figure 2. Earth with latitude (parallels) and longitude (meridians). 
In 1660, Sir Isaac Newton, while revealing a theory of gravity noticed earth's 24-hour rotation. Along with this discovery, he noted the varied gravitational forces, minimum at the pole and maximum at the equator. These discoveries led to the realization of a slightly longer equatorial radius (semi-major) and slightly shorter polar radius (semi-minor) axes. Simply put, parallels are not spaced equally and decrease slightly in spacing from the pole to the equator. The meridians progressively converge from the equator to a point at the North and South Poles. Also, it was realized that the distances measured between two meridians along parallels, decreases from the equator to the poles. With 24 hour a day, there is an hour difference between $15^{\circ}$ longitudes $(360 / 15=24)$; however, due to the differences in the distance between two longitudinal degrees at the poles and equator, the principle of one hour for each $15^{\circ}$ longitudes does not apply. That means the distance between two $15^{\circ}$ longitudes at the poles and equator vary. This is why some places in the northern hemisphere see sun until midnight, for example in Norway. Two longitudes will be closer near the poles than at the equator. Therefore, the distance between two objects standing at two locations on similar longitudinal values at the poles will be nearer than at the equator. Latitudinal values representing locations at the northern pole are represented by positive values $(+$ or $\mathrm{N}$ ) and southern poles with negative values (- or S) and longitudinal values east of central meridians are represented by positive values (+ or E) and west of the central meridians with negative values (- or W) (Figure 3).

Readers often find difficulties in translating the positive and negative values of latitudinal and longitudinal degrees. Thus, the degree values are converted into numerical distances. Based on their cardinal values, these distances also become positive and negative. Since distances are measured with positive numbers, a constant number is added to make negative values positive. For example, in order to make negative longitudinal values positive, values between 500,000 and $10,000,000$ are added in the Universal Transverse Mercator (UTM). Such a value

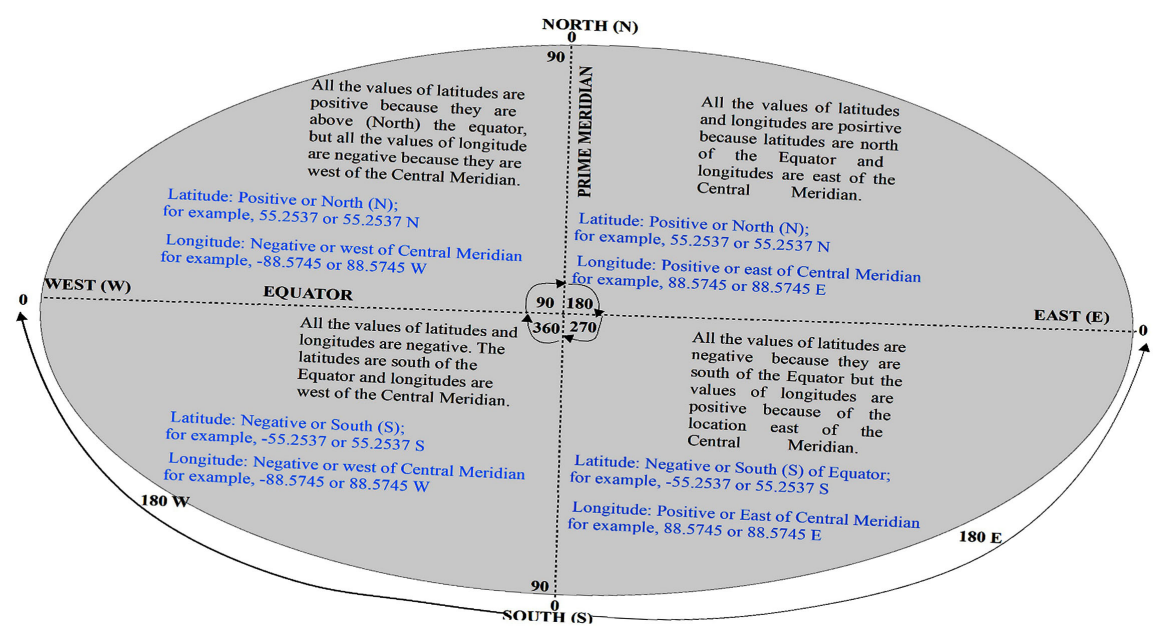

Figure 3. Measuring latitudinal and longitudinal values on four quadrants of globe. 
is called a false easting, meaning that negative longitudinal values are made positive by adding a large number. This false easting is a linear value that is added to all $\mathrm{x}$-coordinates (longitudes) so that none of the longitudinal values being mapped are negative. Likewise, to make latitudinal values positive, a large value called the false northing is added. Depending upon the quadrant, the values of false easting and northing vary ranging from 500,000 to 10,000,000. The false northing and easting numbers vary based on the measurement units such as feet and meters.

After the angular degree decimals are converted to numerical values and are made positive by adding the numerical values of false easting and false northing, locations are traced either east or west (to the right or left) north or south with reference to the point of origin using the standard numerical unit of measure. Such a measurement became possible after the seminal work of French mathematician Descartes, who postulated the theory of the Cartesian Coordinates system. With these developments, the location of an object on the earth is traced based on the angular relationships between latitude and longitude measured in numerical values. Our proposed Transit-Tracker Apps utilize RTI that is based on the relationship between time (longitudinal values) and location-based latitude on the angular relationships; i.e. an angular relationship between latitude and longitude.

Geographic information systems (GIS) handle lines either as vector or as raster through a series of cells. A vector is a quantity that represents both direction and distance (line) with reference to time, and captures the real-time incidence (information) [RTI] along the distance. A Cartesian coordinate gives the vector quantity relative to the origin of the coordinate system. This is how different objects are identified by their distances from the origin and their directions relative to some reference line or point. The direction is known as the bearing and is normally measured clockwise from the north [18]. For example, houses in Kathmandu are numbered by distances from an intersection (crossroad) to the north or south and east or west. All houses are assigned odd numbers on the left and even number on the right. For example, if a house is located 74 meters north or east of a crossroad, such house has a block number $74 \mathrm{~N}$ or $\mathrm{E}$ followed by Ward Number (like a precinct in the US). Though the allocation of even or odd house numbers in the U.S. and Nepal follow similar practices, in the U.S., houses are labeled by numbers, such as 1, 3, 5, 7 on the left and 2, 4, 6 on the right irrespective of the distance from the nearby intersection (crossroad). In Nepal, if a house is built 74 meters away from a crossroad, it is numbered 74 N/2 where 74 is the house number that is 74 meters north from the crossroad and two is the ward number. If another house is built at 25 or 26 meters distance from the crossroad at the later date, the newly built house will get the house number based on the distance from the crossroad. For example, a house built at 25 meters away from a crossroad will get $25 \mathrm{~N}$ or E/2 [Ward number], but in the U. S., if the first built house is numbered 74, the subsequent number would be 75 or 76 
depending upon the left and right of the road if a land plot was not assigned any number before a house was built. By using RTI, not only the location of each household is identified, but also, activities that are happening near any household are tracked. A similar principle is applied to locate the spot of high gaseous emissions, traffic conditions, accidental fatalities, homicides, fire hazards, and locations of health services. Users do not see the numerical RTI (angular or numerical) values on the screen of their devices, but see the names and descriptive activities of any incidences happening in a particular location. The locational information is derived from the Cartesian coordinate system, and the incidences are linked with time, which makes the real-time information (RTI) data. Real-time information (RTI) requires voluminous data points. These data points are linked to sensors operated by high-speed communication networks and open data portals. Apps developers translate raw data (geographic coordinates tied to time) into actions (meaningful information understandable by general users) by feeding these RTI into Apps. The public widely adapt such spatial data and adapt their behaviors according to the outcomes of the data and make their decision choices, for example, the present day GPS locating a certain point and directing users to take a left or right turns or moving forward or backward to reach to the desired destination. Likewise, emergency health workers utilize transit trackers to locate emergency medical cases.

A wide range of Apps application helps cities in functioning "efficiently." Apps designers gather information from high-powered decision makers from almost all parts of a city ecosystem that include city leaders, vendors, academics, researchers, and non-profit organizations through open conversations. Computer programmers utilize such data and convert them into an actionable intelligence to make informed decisions. Further, App designers help process raw data to make them usable in mobile phones, iPads, and computers using the Internet or cloud computing. Smartphones become the keys to the proposed prototype Apps operation. These Apps convert raw data into information about transit, traffic, available health services, safety alerts, and community news, traffic jams, and conditions of pollution, and put data into the hands of millions of users.

In this study, we offer some measures to improve traffic conditions in the Kathmandu Valley by the choice of transportation modes to ameliorate the environment of the Kathmandu Valley by locating the transit media such as bus, using geographic data linked to a location-specific incidence happening at a certain time. Simply put, our goal is to create a safe environment for the public by proposing the Bus Rapid Transit (BRT) system in the Kathmandu Valley. The first step is to find distances between multiple locations and then to develop a schedule for the BRT system for various roads in the Kathmandu Valley. With the implementation of the BRT system, we anticipate a drastic reduction in vehicular emissions by improving the driving speed on the road of Kathmandu Valley. If the rate of current slow speed between 10 and 15 kilometers is in- 
creased up to $45 \mathrm{~km}$ per hour, the levels of emissions would decrease because most vehicles driven between 55 and $75 \mathrm{~km}$ speed limit in urban area would perform better and the amount of emissions also would decrease. The reduction in emissions would help improve the life quality of the Kathmandu Valley with the reduction in hospital visitations for the treatment of various respiratory ailments. Since our model works well in all geographic locations, for example, northeastern, southeastern, southwestern, and northwestern quadrants (Figure 3, Appendices $\mathrm{C}$ ), we argue that this model would have a global applications.

\section{Study Area}

Our study focuses on the capital city-Kathmandu—of Nepal. The Kathmandu Valley expands into three administrative districts (out of 77) of Nepal, namely, Bhaktapur, Kathmandu and Lalitpur (Figure 1). Bhaktapur district covers 123.6 $\mathrm{sq} \cdot \mathrm{km}$, and all the area of this district is fully urbanized and is located within the Kathmandu Valley. Kathmandu district covers $415.5 \mathrm{sq} \cdot \mathrm{km}$ of which 85 percent of the area is urbanized. Lalitpur district covers $397.4 \mathrm{sq} \cdot \mathrm{km}$ of which 50 percent is urbanized. The total urbanized area within the Kathmandu Valley is 675.5 $\mathrm{sq} \cdot \mathrm{km}$.

Mountains and hillocks of various heights ranging from 2300 to 2800 meters (m) surround the Kathmandu Valley [19]. These pristine hills surrounding the Valley used to be serene and look blue around two decades ago, but now appear gray and hazy because of the "stagnant smog that hovers over them" [20]. The majority of the Valley area is within the range of $1300 \mathrm{~m}$ elevation, where summer temperature ranges from $9^{\circ} \mathrm{C}$ to $27^{\circ} \mathrm{C}$ and winter temperature ranges from $2^{\circ} \mathrm{C}$ to $20^{\circ} \mathrm{C}$. In average, the Valley's air has 75 percent humidity. In the winter, around November, about $7 \mathrm{~mm}$ of rainfall occurs and in July, the rainfall goes up to $364 \mathrm{~mm}$. The mean precipitation between July and September is about $2000 \mathrm{~mm}$. The bowel shaped Valley (Figure 4) generally remains calm and its atmospheric layers closer to the surface are less disturbed holding the polluting particulates into the atmosphere [21] [22] [23].

Traditionally, Kathmandu was a pedestrians and cyclists city. The Valley denizens largely relied on walking; some bicycled, others used public transportation that was managed by corporate bodies such as Sajha Yatayat (Common Transport mode). After the construction of the ring road, urban sprawl started, and many houses were built everywhere in the Valley. The newly developed areas lacked any reliable transportation services. The unmanaged sprawl caused by the construction of the ring road with haphazard buildings without any urban planning lacks reliable transportation services. Especially, with the remittance propelled economy since the 1990s [24] [25] [26] [27] [28] made the Kathmandu Valley's environment much worse as more and more houses are added along with the addition of other concrete infrastructures that increased the albedo. Consequently, motorized vehicles grew in large numbers each year to fill the void created by the lack of a mass transit policy or any implementation thereof. 
Overtime, with the growth of population, the Valley transit system is becoming unmanageable and very crowded as in Bangkok, Thailand (Plates 1(a)-(f)). The transit system is very unreliable. Road construction has been very haphazard and pollution level is too high both from vehicles and constructional work (Plate 2).
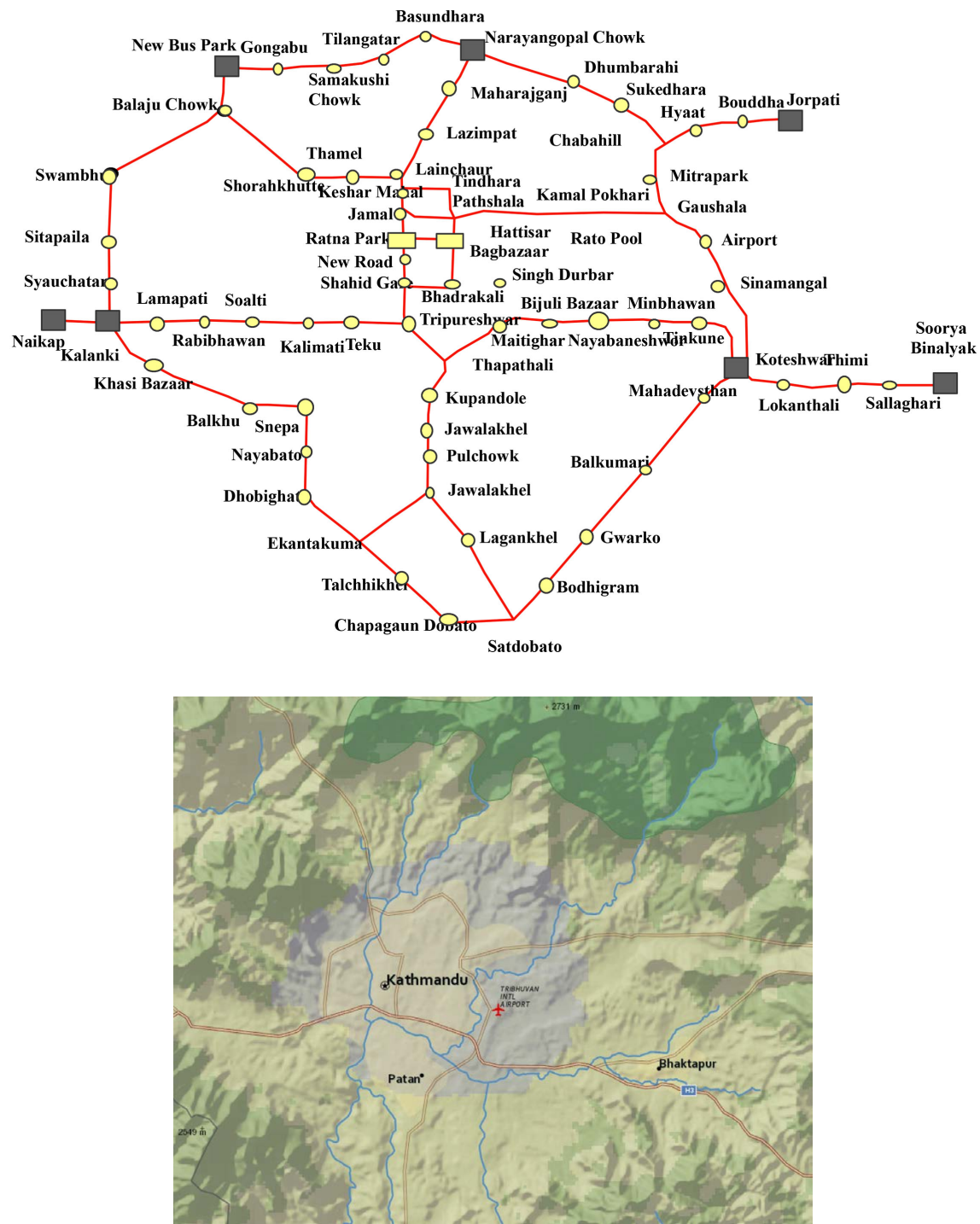

Figure 4. Kathmandu Valley. Inner streets and feeder roads are seen in white color.

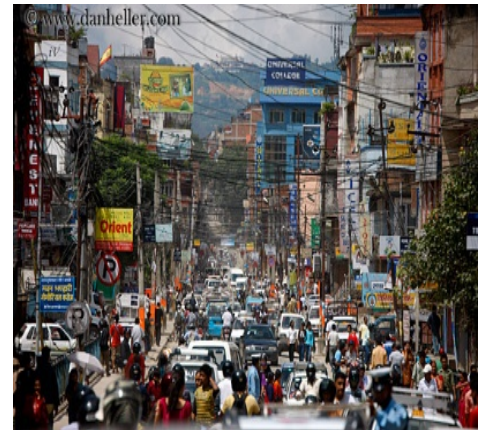

(a)

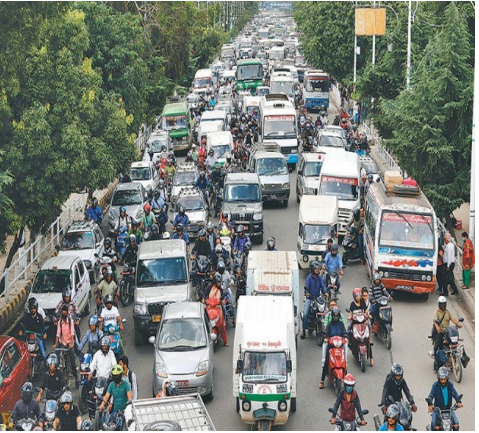

(b) 


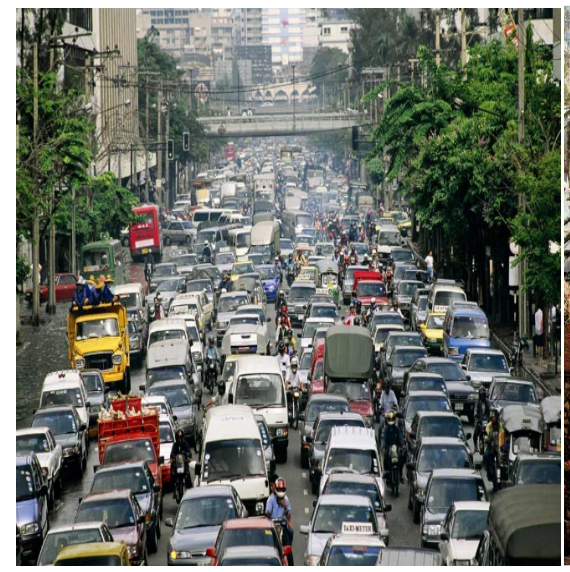

(c)

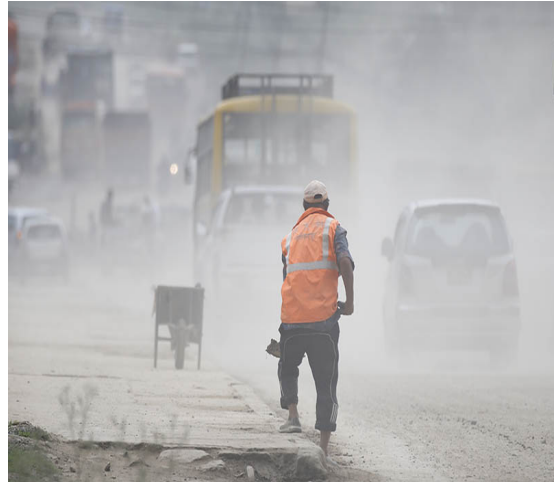

(e)

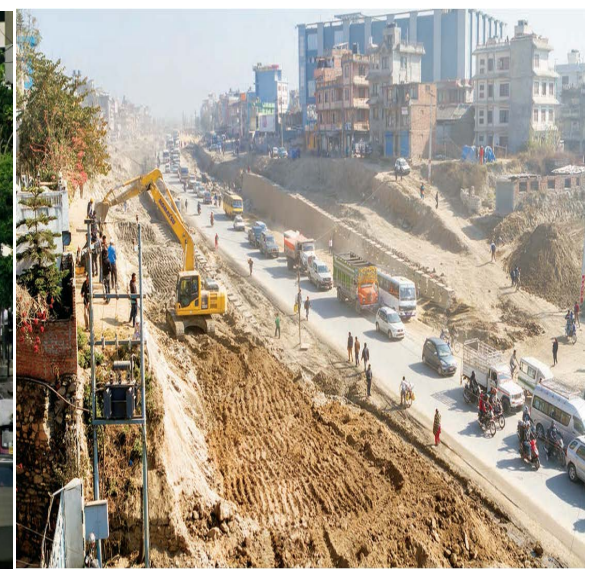

(d)

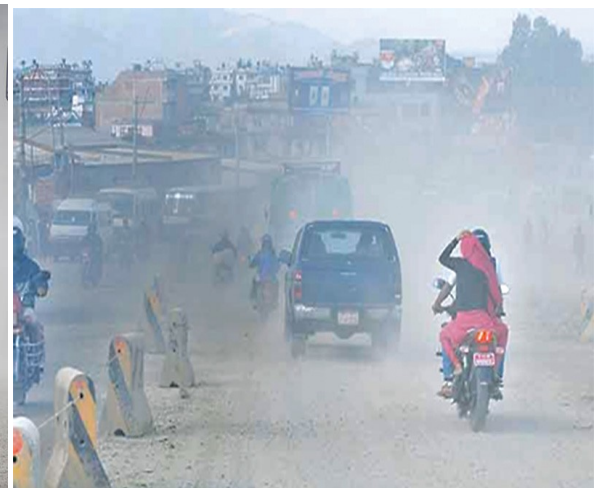

(f)

Plate 1. (a) Traffic in Lalitpur; (b) Traffic in Kathmandu; (c) Traffic in Bangkok; (d) Road widening in Kathmandu; (e) Pollution due to vehicles and constructions; (f) Emissions from vehicles and constructions.

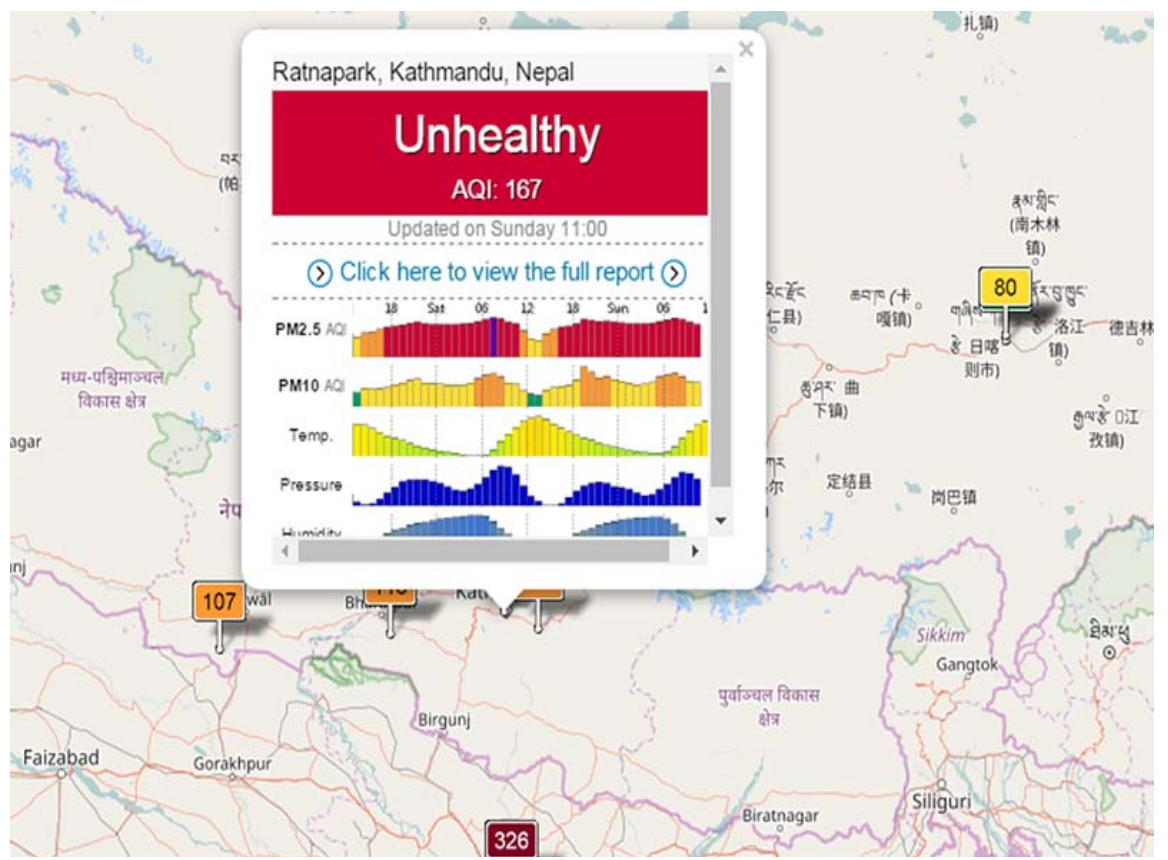

Plate 2. Pollution in Kathmandu. 
There is no reliable population record for the Kathmandu Valley to plan exactly how many people live in this crowded Valley and how many need regular transit services. Between census years 1991 and 2001, a population of 0.52 million was added to the Valley. Over the next decade, the total population rose by another 0.83 million. In two decades, the census population of the Valley more than doubled from 1.07 million in 1991 to 2.43 million in 2011 [29]. These figures do not include floating (student and tourist) populations. Based on the count of the dwelling units [30], an estimated 4 million people, or probably more, now live in the Valley at any given time [29].

Vehicle ownership has also grown up in proportion with the population. The population concentration has increased during the Maoist ten years (1996-2006) countryside's insurgency. There is no exact record of the total population of the Kathmandu Valley, but various estimates put it between 4 and 5.5 million [31] [32]. Despite such concentrated population, the Valley's transit systems are poorly managed on the unplanned streets (Figure 4, white lines). Both pedestrians and drivers face multiple problems.

There are no standard sidewalks. Existing sidewalks are poorly built and ill-managed. Some intersections are very dangerous. In 2018, a survey by the Resource Centre for Primary Health Care (RCPHC) of 35 different sections of the Kathmandu Metropolitan showed that more than 70 percent of roads do not have basic amenities for pedestrians. The same survey revealed that more than 70 percent of respondents were afraid of crossing the road while more than 40 percent reported to have multiple incidents and injuries due to the lack of sidewalks of minimum width, crosswalks, traffic lights and handrails [33]. Almost 80 percent of the roads do not have zebra crossings. Pedestrians have to wait frustratingly because of no traffic lights to regulate vehicles at various crossings, where both drivers and pedestrians get confused. Many footpaths are very narrow, four to six feet or less in width, and these too have several obstructions from electric poles (pillars) and telephone poles and cables. Besides, there are shops, construction materials, trees, trashcans and vendors that obstruct the movement of pedestrians. The National Road Standard suggests having a minimum width of 1.5 meters $(\sim 5 \mathrm{ft}$.) for footpaths and 1.8 meters $(\sim 6 \mathrm{ft}$.) width for a passing zone, and 2 meters (6.6 ft.) of foot paths width at every 50 meters ( 164 $\mathrm{ft})$ in case of a narrower footpath. Additionally, a densely populated area needs at least 2 ( $\sim 6.6 \mathrm{ft}$.) to 2.5 meters $(\sim 8.2 \mathrm{ft}$.) width of pedestrian road. Footpaths are an integral component of standard roads, and they should follow certain standards [34]. "The unplanned road-widening in 2013, actually reduced footpaths in many places and gave way to vehicles at the cost of pedestrians. It is clear that these ad-hoc actions ignored the larger city planning and most importantly, the reality that Kathmandu was a highly pedestrian city [34]. In 172 locations, road is expanded without any planning even encroaching the security walls of petrol pumps. Such a practice of expanding road has made petrol pumps operations in the Kathmandu Valley into safety hazards [35]. 
In order to facilitate the road crossings, over 14 movable overhead bridges are installed in high traffic zones of the Valley, but many of them are in dilapidated conditions, and are very unfriendly to older adults. Open spaces are shrinking in the Kathmandu Valley. Though roads are expanded in some places, such expansions have created additional problems even by merging with footpaths, especially, without proper crossings and merging intersections; for example, several portions of roads recently remodeled from the Chinese aid from Koteshwor to Kalanki section of the Kathmandu Valley have the large number of accidental incidences. This widening has increased vehicular speeds with the increase in pedestrians' casualties [33]. Due to overcrowding of traffic followed by the poor regulations across the Valley, over 27,150 accidents incidences are recorded annually with an average of 624 deaths, and about 1157 serious injuries per year [33]. Of the deceased, around 300 are pedestrians followed by motorcyclists. Already congested traffic during the peak period (Table 1) has become much worse with the addition of many vehicles (Table 2 ) beyond the carrying capacity in the Katmandu Valley. The well-to-do families own low occupancy vehicles such as motorcycles, cars, and three wheelers. The purchase of motorbikes has increased by 2.40 times and cars by 1.72 times (Table 2). These additions of vehicles on crowded spaces are making the traffic of the Kathmandu Valley one of the most unmanageable in Asia [29]. It is projected that many more vehicles will be added by 2021, 2025, 2031, and 2034 (Table 2). Already existing old vehicles that operate on leaded petroleum products including diesel emit a large volume

Table 1. Traffic Volume and Annual Average Daily Traffic.

\begin{tabular}{|c|c|c|c|c|c|c|c|c|c|c|}
\hline \multirow[t]{2}{*}{ Vehicle type } & \multicolumn{5}{|c|}{ Traffic Volume (2009) } & \multicolumn{5}{|c|}{ Traffic Volume (2021) } \\
\hline & Peak & Off-Peak & $\mathrm{AADT}^{1}$ & $\begin{array}{l}\text { Total } \\
(\%)\end{array}$ & $\begin{array}{l}\text { Passenger } \\
\text { occupancy }\end{array}$ & Peak & Off-Peak & $\mathrm{AADT}^{1}$ & Total (\%) & $\begin{array}{l}\text { Passenger } \\
\text { occupancy }\end{array}$ \\
\hline Motorcycle & 50,954 & 178,648 & 297,747 & 64 & 1.3 & 89,169 & 312,634 & 521,057 & 71.0 & 1.3 \\
\hline Car & 9168 & 38,708 & 64,513 & 14 & 2.5 & 11,460 & 48,385 & 80,641 & 11.0 & 2.5 \\
\hline Taxi & 3745 & 15,810 & 26,351 & 6 & 1.4 & 5618 & 23,715 & 39,527 & 5.3 & 1.4 \\
\hline Utility & 4046 & 17,783 & 29,638 & 6 & & 5058 & 22,229 & 37,048 & 5.0 & \\
\hline Big Bus & 190 & 1388 & 2314 & 1 & 33 & 285 & 2082 & 3471 & 0.47 & 35 \\
\hline Minibus & 1371 & 6443 & 10,738 & 2 & 26.4 & 1714 & 8054 & 13,423 & 1.8 & 27 \\
\hline Microbus & 2470 & 10,892 & 18,153 & 4 & 12.3 & 3088 & 13,615 & 22,692 & 3.1 & 13 \\
\hline Safa Tempo & 1818 & 5828 & 9714 & 2 & 7.6 & 7285 & 7285 & 12,143 & 1.7 & 8 \\
\hline Heavy Truck & 50 & 829 & 1382 & 0 & & 85 & 1409 & 2350 & 0.32 & \\
\hline Light Truck & 45 & 827 & 1378 & 0 & & 75 & 2297 & 2297 & 0.31 & \\
\hline Total & 73,855 & 271,328 & 461,927 & 100 & & 123,837 & 441,705 & 734,649 & 100 & \\
\hline
\end{tabular}

AADT $\rightarrow$ Annual average daily traffic. The projections are based on the trends of vehicles registered with government agencies. The average increases are between 0.80 and 1.75 for passenger transport, 1.25 for freight transport, and 2.00 for motorcycles. Source: Technical Assistance to Nepal for preparing the Kathmandu Sustainable Transport Project under (TA7243-REG) preparing the implementation of Asian City Transport-Promoting Sustainable Urban Transport in Asia estimate. 
Table 2. The Number of Vehicles in Different years. (Estimates based on the annual traffic growth around 5 percent for trucks, and 7 percent for others).

\begin{tabular}{lccccccccccc}
\hline \multicolumn{10}{c}{ Annual vehicle numbers: 2009-2034 } & & \\
\hline Year & Truck & $\begin{array}{c}\text { Light } \\
\text { Truck }\end{array}$ & Bus & Mini Bus Micro Bus Car Taxi & Utility & $\begin{array}{c}\text { Safa } \\
\text { Tempo }\end{array}$ & $\begin{array}{c}\text { Motor- } \\
\text { cycle }\end{array}$ & Total \\
2009 & 1382 & 1378 & 2314 & 10,738 & 18,153 & 90,868 & 29,638 & 9714 & 297,747 & 461,927 \\
2015 & 1853 & 1847 & 3473 & 16,114 & 27,242 & 136,362 & 41,568 & 14,578 & 446,838 & 689,878 \\
2021 & 2483 & 2475 & 5154 & 23,913 & 40,427 & 193,432 & 58,965 & 20,679 & 565,392 & 912,921 \\
2025 & 3018 & 3009 & 6705 & 31,112 & 52,596 & 244,203 & 74,442 & 26,107 & 661,429 & $1,102,622$ \\
2031 & 4044 & 4032 & 9950 & 46,169 & 78,052 & 326,799 & 105,598 & 37,034 & 799,027 & $1,430,313$ \\
2034 & 4681 & 4668 & 12,121 & 56,243 & 95,082 & 412,577 & 125,769 & 44,108 & 878,214 & $1,633,462$ \\
\hline & & & & Annual Passenger Number $2009-2034$ & & & \\
\hline 2009 & & & 76,364 & 264,148 & 223,277 & 198,084 & & 70,912 & 387,071 & $1,219,856$ \\
2015 & & & 114,602 & 396,414 & 335,079 & 297,269 & & 106,421 & 580,889 & $1,830,674$ \\
2021 & & & 170,067 & 588,270 & 497,250 & 421,682 & & 150,960 & 735,010 & $2,563,239$ \\
2025 & & & 221,261 & 765,563 & 646,934 & 532,363 & & 190,583 & 859,858 & $3,216,351$ \\
2031 & & 328,347 & $1,135,767$ & 960,036 & 712,422 & & 270,346 & $1,038,735$ & $4,445,652$ \\
2034 & & 399,987 & $1,383,576$ & $1,169,503$ & 899,418 & & 321,986 & $1,141,678$ & $5,316,149$ \\
\hline
\end{tabular}

of emissions. Though the concerns of vehicular emissions started from the late 1960s even when there were rarely any vehicles plying on the roads of the Kathmandu Valley, the situation has never been as serious as it is today. In 1965, the Motor Vehicle Air Pollution Control Act was enacted. In 1967, the Air Quality Act was introduced, and the emission regulations for cars started under the Clean Air Act of 1968. In 1970, the Clean Air Act was amended to set the standard of National Ambient Air Quality. Despite these attempts, positive effects of these Acts and Laws are rarely seen in Nepali traffic and environmental management.

On one hand, the atmospheric gaseous concentration in the bowl-shaped Kathmandu Valley has increased without any wind turbulence, and on the other hand, the addition of concrete structures increases albedo that reflects the surface light. The thick fog/smog in the early part of the day (around 11am), the wind and higher ground-level temperatures act to break the temperature inversion and trap the pollution. Nearly every night in winter, this pollution event repeats itself. More pollutants are trapped during the winter than during the spring and autumn because the brick factories are only operational during the winter when there is no rain. Though spring and autumn episodes of air pollution in Kathmandu are not as severe as in winter, still they can certainly cause health problems from the fine dust particles fumigated into the atmosphere after dust particles are crushed into fine pieces by over 500,000 vehicles plying in the 
valley's roads. The polluted air does not escape from the atmosphere. As the pollutants are trapped to the atmosphere, heat islands are created in densely populated areas with taller buildings (Figure 5). The mild climatic conditions of the Kathmandu Valley becomes like subtropical and even tropical humid types of climate between the months of June and August. The Government of Nepal (GoN) has not been able to keep pace with the rapid increase in demand for building construction, road infrastructure and other types of services due to the tremendous population growth. The GoN has taken some steps to improve the environment, for example, relocating the large existing industries from the Valley, such as Himal Cement factory from Chobhar, distilling industry from Balaju and leather tanning industries from Bansbari are now being relocated either outside the city or being closed down [36] for good. While these government policies have definitely curtailed the frequency of severe air pollution in Kathmandu, it has not solved the problems of vehicular emissions.

Kathmandu air is very polluted, and it is getting much more polluted over time (Plate 2). For example, toward the end of 2013, the $\mathrm{PM}_{10}$ particulates were 260 micrograms per cubic meter $\left(260 \mu \mathrm{g} / \mathrm{m}^{3}\right)$ against a maximum limit of 40 $\mu \mathrm{g} / \mathrm{m}^{3}$ as recommended by WHO [37]. In 2014, $\mathrm{PM}_{10}$ particulates increased to $400 \mu \mathrm{g} / \mathrm{m}^{3}$ against the WHO's set National Ambient Air Quality Standards of $120 \mu \mathrm{g} / \mathrm{m}^{3}$ [38]. These samples were from Putali Sadak /Ratna Park (Plate 2) and Tripureshwor (Figure 5). In 2015, Kathmandu was ranked as the fifth polluted city in the world [39]. In 2016, Kathmandu was ranked (96.66) as the third most polluted city in Asia on the Pollution Index 2016 [21] [39] [40]. These pollutants have caused a variety of respiratory and other diseases, some of which have become fatal [41]. Dust particles generally result in particulate matters $\left(\mathrm{PM}_{10}\right)$ that remain suspended in the atmosphere. These particulates cause irritation to the eyes, nose, and causes acute respiratory infections [42] [43]. Even more harmful are the $\mathrm{PM}_{2.5}$ particulates that penetrate deep into the lungs, irritate, and corrode the alveolar wall, "consequently impair lung function" [44], and "even penetrate [into] the blood" [45] [46]. The high concentration of CO in the blood increases carboxyhemoglobin $(\mathrm{COHb})$ that leads to heart attacks, and affects the nervous system. Nitrous oxide $\left(\mathrm{NO}_{2}\right)$ emitting from vehicles causes bronchitis and bronchopneumonia, and $\mathrm{SO}_{2}$ causes eye irritation and conjunctivitis [47]. These gases cause shortness of breath, chronic bronchitis, asthma, and even lung cancer [45]. Because of the over accumulation of $\mathrm{PM}_{2.5}$ particulates cause these diseases, it is suspected that the life expectancy in the Kathmandu Valley has decreased [48] [49] [50].

It is necessary to find some solutions to ameliorate the atmospheric conditions of the Kathmandu Valley by improving the urban transit system. We propose to replace the low occupancy vehicles with high occupancy vehicles in order to reduce the per capita pollutant emission in the Kathmandu Valley. It is necessary to reverse or retard the increasing trends of vehicle registration that has been on the rise in successive years, for example, in 2021, 2025, 2031, and 2034 (Table 2). 


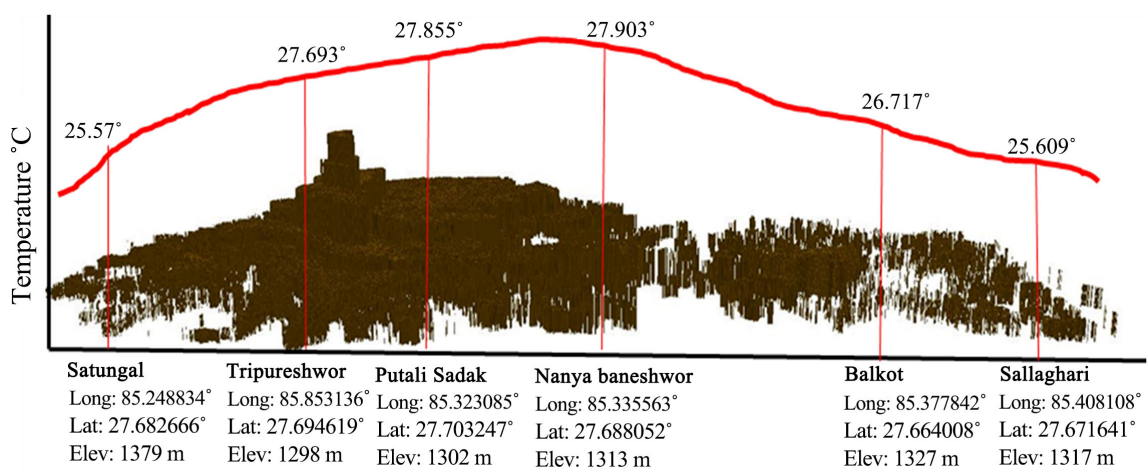

Figure 5. Urban heat in Kathmandu.

In order to discourage the rapid increase of vehicles in the Kathmandu Valley, some stringent measures such as restrictions on private car and motorcycle usages in the city center may be necessary. This can be done by pedestrianization and restricting the parking facilities, and informing people about the cost of various transport modes (Table 3). Such information would also help planners and policymakers for long-term transportation for the Kathmandu transit system. Replacing low occupancy vehicles with high occupancy vehicles and increasing their frequencies of operations would help to reduce traffic congestions, reduce the number of accidents, reduce gaseous emissions, which will help not only in improving air quality, but also in travel reliability. Simply put, limiting the number of vehicles on the street and using high occupancy vehicles with fixed schedules (Appendix B) would help in the reduction of cost, time, emission, and traffic jams. In order to achieve these goals, we have proposed to use a decision-aiding Transit-Tracker methodology for bus scheduling using real-time information (RTI).

Implementing an urban transit system will be a challenge because the transit syndicates have made a very strong comprador with various investors, who in the past have repeatedly blocked official attempts to modernize the highly inefficient bus network of the Kathmandu Valley and other urban areas of Nepal [51]. Because of their strong nexus with various political forces, these syndicates have managed to take control over the roads. In order to ensure that the future laws are favorable to them, they have been successful at sending off politicians extremely loyal to them to the parliament and different levels of governments through donations to key political figures and/or parties. Such representatives are elected either through open competition or through the proportional nomination system [52] [53]. Starting from 2012, the Asian Development Bank proposed implementing a six-year program to replace low occupancy with high occupancy vehicles [54]. There are speculations that both politicians and government employees are behind the failure of the ADB's proposed transit improvement plan. The transportation syndicate have lobbied government authorities and politicians through 3-M (money, muscle and mask-pretending to be people's representative, but working clandestinely for transit syndicates). The corruption is so rampant that Nepal currently ranked 124 out of 175 countries in 
the watchdog Transparency International's global corruption perception index [55]. By various means, over 10,000 buses and minibusses in various conditions ply over the streets of the Kathmandu Valley [51]. These vehicles use lead-containing gasoline and diesel at various rates when operated in different speeds (Table 3) and emit pollutants (Table 4). Since these vehicle operate below normal levels (slow speed and traffic jams), they emit tremendous amounts of fumes, but none provide efficient services.

Table 3. Urban Vehicle Operating Costs "Stop-Start" Conditions (Cost in Nepali rupees/ $\mathrm{km})$.

\begin{tabular}{cccccccccccc}
\hline \multicolumn{2}{c}{ Cost (in rupees "Rs", Rs. $109=\$ 1.00)$ per kilometer using various modes of transportation } \\
\hline $\begin{array}{c}\text { Average } \\
\text { speed } \\
(\mathrm{km} / \mathrm{hr})\end{array}$ & $\begin{array}{c}\text { Motor } \\
\text { cycle }\end{array}$ & Car & Utility & $\begin{array}{c}\text { Light } \\
\text { Truck }\end{array}$ & Truck & $\begin{array}{c}\text { Multi-axle } \\
\text { Truck }\end{array}$ & $\begin{array}{c}\text { Micro- } \\
\text { bus }\end{array}$ & $\begin{array}{c}\text { Mini- } \\
\text { Bus }\end{array}$ & Bus & $\begin{array}{c}\text { Safa } \\
\text { Tempo }\end{array}$ \\
\hline 10 & 4.62 & 22.30 & 26.11 & 37.62 & 45.18 & 43.67 & 36.22 & 30.84 & 40.52 & 8.77 \\
15 & 4.28 & 20.56 & 23.84 & 34.26 & 41.43 & 39.88 & 33.26 & 28.43 & 37.04 & 8.13 \\
20 & 3.91 & 18.68 & 21.38 & 30.59 & 37.18 & 35.62 & 30.17 & 25.82 & 33.32 & 7.43 \\
25 & 3.55 & 16.80 & 18.92 & 26.91 & 32.94 & 31.36 & 27.08 & 23.21 & 29.59 & 6.74 \\
30 & 3.18 & 14.91 & 16.45 & 23.24 & 28.70 & 27.11 & 23.99 & 20.59 & 25.86 & 6.05 \\
35 & 2.82 & 13.03 & 13.99 & 19.57 & 24.45 & 22.85 & 20.89 & 17.98 & 22.13 & 5.35 \\
40 & 2.45 & 11.15 & 11.53 & 15.90 & 20.21 & 18.59 & 17.80 & 15.37 & 18.41 & 4.66 \\
45 & 2.09 & 9.27 & 9.06 & 12.23 & 15.96 & 14.33 & 14.71 & 12.76 & 14.68 & 3.97 \\
50 & 1.72 & 7.39 & 6.60 & 8.56 & 11.72 & 10.08 & 11.62 & 10.15 & 10.95 & 3.27 \\
\hline
\end{tabular}

Source: Technical Assistance to Nepal for Preparing the Kathmandu Sustainable Transport Project under (TA7243-REG) Preparing the Implementation of Asian City Transport-Promoting Sustainable Urban Transport in Asia estimates.

Table 4. Total gas (liters) consumed by different vehicles in the Kathmandu Valley (2009-2034).

\begin{tabular}{cccccccc}
\hline \multirow{2}{*}{ Vehicle Types } & \multicolumn{7}{c}{ Various vehicles operating in different years in the Valley } \\
\cline { 2 - 8 } & 2009 & 2015 & 2021 & 2025 & 2031 & 2034 & Total \\
\hline Truck & 1382 & 1853 & 2483 & 3018 & 4044 & 4681 & 17,461 \\
Light Truck & 1378 & 1847 & 2475 & 3009 & 4032 & 4668 & 17,409 \\
Bus & 2314 & 3473 & 5154 & 6705 & 9950 & 12,121 & 39,717 \\
Minibus & 10,378 & 16,114 & 23,913 & 31,112 & 46,169 & 56,243 & 183,929 \\
Microbus & 18,153 & 27,242 & 40,427 & 52,596 & 78,052 & 95,082 & 311,552 \\
Car Taxi & 90,868 & 136,362 & 193,432 & 244,203 & 326,799 & 412,577 & $1,404,241$ \\
Utility & 29,638 & 41,568 & 58,965 & 74,442 & 105,598 & 125,769 & 435,980 \\
Safa Tempo & 9714 & 14,578 & 20,679 & 26,107 & 37,034 & 44,108 & 152,220 \\
Motorcycle & 297,747 & 446,368 & 565,392 & 661,429 & 799,027 & 878,214 & $3,648,177$ \\
Total & 461,932 & 689,405 & 912,920 & $1,102,621$ & $1,410,705$ & $1,633,463$ & $6,211,046$ \\
\hline
\end{tabular}


An analysis of vehicle trips, consumption of gases, speed limits, and types of vehicles suggest that the ADB plan would have significantly reduced congestion and emissions in the transit of the Kathmandu Valley (Table 5 and Table 6; Figure 6). It would have helped bringing down the concentration of $\mathrm{PM}_{2.5}$ particulates to below $150 \mu \mathrm{mg} / \mathrm{m}^{3}$. Yet, this $150 \mu \mathrm{mg} / \mathrm{m}^{3}$ is much higher than the WHO recommended level of $120 \mu \mathrm{mg} / \mathrm{m}^{3}$. However, the owners of the low occupancy vehicles (National Federation of Nepal Transport Entrepreneurs-NFTE-an umbrella group for the bus operators) argued that the ADB plan amounted to "bullying small investors." The NFTE rather challenges the ADB and Kathmandu Sustainability Urban Transportation Project (KSUTP) to enter open competition with NFTE rather than replacing the low occupancy vehicles. According to NFTE, the replacement of low occupancy vehicles with high occupancy ones will be a dire injustice to the investors [53]. Amidst these controversies, the trend of vehicle registration is on the rise and projected to increase by 2021, 2025, 2031, and 2034 (Table 2). These estimates are based on the annual traffic growth around 5 percent for trucks and 7 percent for other types of vehicles.

Table 5. Gaseous emission by various vehicles in tons (2009-2034).

\begin{tabular}{cccccccc}
\hline Vehicles & Emissions $/ \mathrm{km}$ & 2009 & 2015 & 2021 & 2025 & 2031 & 2034 \\
\hline Truck & 285 & 33.48 & 44.89 & 60.15 & 73.11 & 97.97 & 113.40 \\
Light Truck & 185 & 22.94 & 30.75 & 41.21 & 50.10 & 67.13 & 77.72 \\
Bus & 188 & 130.51 & 195.88 & 290.69 & 378.16 & 561.18 & 683.62 \\
Mini Bus & 133 & 314.19 & 471.50 & 699.69 & 910.34 & 1350.90 & 1645.67 \\
Micro Bus & 109 & 395.74 & 593.88 & 881.31 & 1146.59 & 1701.53 & 2072.79 \\
Car Taxi & 75 & 1192.64 & 1789.75 & 2538.80 & 3205.16 & 4289.24 & 5415.07 \\
Utility & 264 & 665.08 & 932.79 & 1323.17 & 1670.48 & 2369.62 & 2822.26 \\
Motor-cycle & 60 & 1161.21 & 1742.67 & 2205.03 & 2579.57 & 3116.21 & 3425.03 \\
& Total & $\mathbf{3 9 1 5 . 7 9}$ & $\mathbf{5 8 0 2 . 1 0}$ & $\mathbf{8 0 4 0 . 0 5}$ & $\mathbf{1 0 , 0 1 3 . 5 2}$ & $\mathbf{1 3 , 5 5 3 . 7 8}$ & $\mathbf{1 6 , 2 5 5 . 5 7}$ \\
\hline
\end{tabular}

Table 6. Percentages contributions to gas emissions by various vehicles within the Kathmandu Valley in different years.

\begin{tabular}{|c|c|c|c|c|c|c|}
\hline \multirow{2}{*}{ Vehicle Types- } & \multicolumn{6}{|c|}{ Percentages of gas } \\
\hline & 2009 & 2015 & 2021 & 2025 & 2031 & 2034 \\
\hline Truck & 0.85 & 0.77 & 0.75 & 0.73 & 0.72 & 0.70 \\
\hline Light Truck & 0.59 & 0.53 & 0.51 & 0.50 & 0.50 & 0.48 \\
\hline Bus & 3.33 & 3.38 & 3.62 & 3.78 & 4.14 & 4.21 \\
\hline Minibus & 8.02 & 8.13 & 8.70 & 9.09 & 9.97 & 10.12 \\
\hline Microbus & 10.11 & 10.24 & 10.96 & 11.45 & 12.55 & 12.75 \\
\hline Car Taxi & 30.46 & 30.85 & 31.58 & 32.01 & 31.65 & 33.31 \\
\hline Utility & 16.98 & 16.08 & 16.46 & 16.68 & 17.48 & 17.36 \\
\hline Motorcycle & 29.65 & 30.04 & 27.43 & 27.76 & 22.99 & 21.07 \\
\hline Total & 100 & 100 & 100 & 100 & 100 & 100 \\
\hline
\end{tabular}




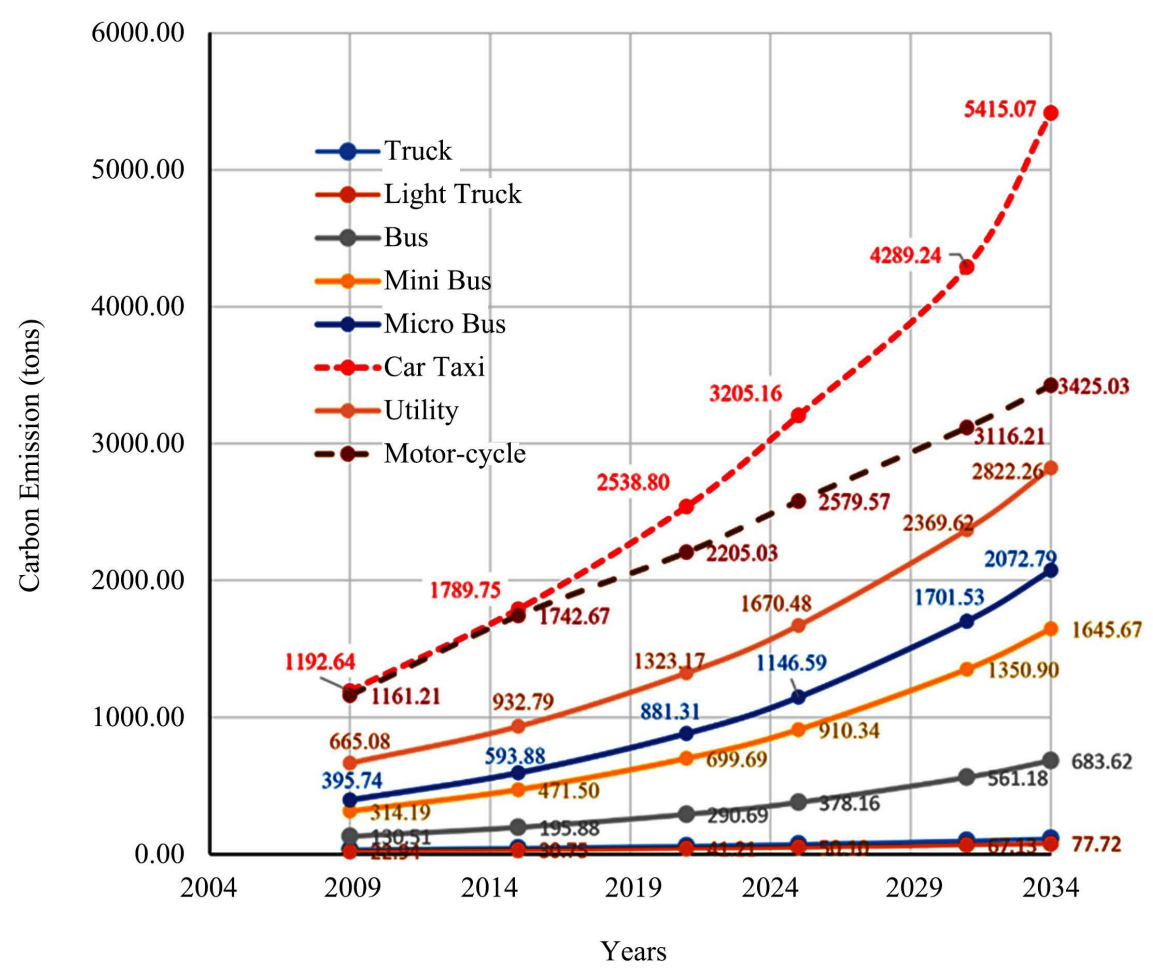

Figure 6. Carbon emissions (tons) by various vehicles (2009-2034).

\section{Assumptions for the Kathmandu Valley}

- 1 liter (L) of petrol weighs 750 grams. Petrol consists for 87 percent of carbon, or 652 grams of carbon per liter of petrol. In order to combust this carbon to $\mathrm{CO}_{2}, 1740$ grams of oxygen is needed. The sum is then $652+1740=$ 2392 grams of $\mathrm{CO}_{2} /$ liter of petrol.

- A motorcycle yields $40 \mathrm{~km}$ by consuming a liter of petrol in an average. In an average, a motorcycle covers $60 \mathrm{~km} /$ day in the Kathmandu Valley. An average consumption of $1.5 \mathrm{~L} / 60 \mathrm{~km}$ then corresponds to $1.5 \mathrm{~L} \times 2392 \mathrm{gram} / \mathrm{L}$ per $60 \mathrm{~km}$ - 60 gram $\mathrm{CO}_{2} / \mathrm{km}$.

- A carcovers $32 \mathrm{~km}$ distance by consuming a liter of petrol in an average. In an average, a car covers $75 \mathrm{~km} /$ day. An average consumption of $2.34 \mathrm{~L} / 75 \mathrm{~km}$ then corresponds to $2.34 \mathrm{~L} \times 2392$ grams/L for $75 \mathrm{~km}-75$ grams $\mathrm{CO}_{2} / \mathrm{km}$.

- A microbus travels $22 \mathrm{~km}$ by consuming a liter of petrol in an average. In an average, a microbus covers $200 \mathrm{~km} /$ day. An average consumption of 9.09 liters $/ 200 \mathrm{~km}$ then corresponds to $9.09 \mathrm{~L} \times 2392$ gram/L per $200 \mathrm{~km}-109$ grams of $\mathrm{CO}_{2} / \mathrm{km}$.

- A minibus travels $18 \mathrm{~km}$ by consuming a liter of petrol in an average. In an average, a minibus covers $220 \mathrm{~km} /$ day. An average consumption of 12.22 $\mathrm{L} / 220 \mathrm{~km}$ then corresponds to $12.22 \mathrm{~L} \times 2392$ gram/L per $220 \mathrm{~km}-133$ gram of $\mathrm{CO}_{2} / \mathrm{km}$.

- A liter of diesel weighs 835 grams. Diesel consists for 86.2 percent of carbon, or 720 grams of carbon per liter. About 1920 grams of oxygen in needed to 
combust a liter of diesel. Thus, a liter of diesel combustion will emit $720+$ $1920=2640$ grams, i.e. 2640 grams of $\mathrm{CO}_{2}$ per liter of diesel.

- A truck travels in average $9.36 \mathrm{~km}$ by consuming a liter of diesel. In an average, a truck would cover $85 \mathrm{~km}$ a day in the Kathmandu Valley. An average consumption of 9.08 liters $/ 85 \mathrm{~km}$ then corresponds to $9.08 \mathrm{~L} \times 2640$ grams/Lper $85 \mathrm{~km}$ - 285 grams of $\mathrm{CO}_{2} / \mathrm{km}$.

- A light truck travels up to $12.90 \mathrm{~km}$ by consuming a liter of diesel. In an average, a light truck in Kathmandu covers $90 \mathrm{~km}$ in a day. An average consumption of 6.96 liters to cover $90 \mathrm{~km}$ of distance. That means to $6.96 \mathrm{~L} \times$ 2640 grams/L per $90 \mathrm{~km}-185$ grams of $\mathrm{CO}_{2} / \mathrm{km}$.

- A utility vehicles travels up to $10 \mathrm{~km}$ by consuming a liter of diesel. In an average, a utility vehicle in Kathmandu covers $85 \mathrm{~km}$ in a day. An average consumption of 8.5 liters to cover $85 \mathrm{~km}$ of distance. That means to $8.5 \mathrm{l} \times 2640$ $\mathrm{g} / \mathrm{l} / 85$ (per km) - $264 \mathrm{~g} \mathrm{CO}_{2} / \mathrm{km}$.

- A bus yields up to $14 \mathrm{~km}$ by consuming a liter of diesel. In an average, a bus in Kathmandu covers $300 \mathrm{~km}$ in a day. An average consumption of $21.42 \mathrm{~L}$ to cover $300 \mathrm{~km}$ of distance. That means to $21.42 \mathrm{~L} \times 2640$ grams $/ \mathrm{L}$ per300 km 188 grams of $\mathrm{CO}_{2} / \mathrm{km}$.

- Per capita gaseous emissions in grams by various vehicles per year vary; for example, Bus $\rightarrow$ 1709, Mini Bus $\rightarrow$ 1407, Micro-bus $\rightarrow$ 1772; Car-Taxi $\rightarrow$ 6021; Motorcycle $\rightarrow 3000$.

Article 30 (1) of Nepal's Constitution 2015, guarantees that each citizen shall have the right to live in a clean and healthy environment and enjoy compensation from the polluting agents for the harm they are caused by pollution. The National Human Rights Commission (NHRC) recommended that the government develops a schedule comprising the date of commencement for the implementation of high occupancy bus services. It recommends that all vehicle operators must abide by pollution control measures as set forth in the laws as per the Constitution of Nepal 2015. The NHRC asked the government to formulate a law empowering the concerned authorities to impose on-the-spot fines on vehicles for not meeting the existing emission standards. Nepal can learn a lesson from Indian example. For example, in Bangalore where the Bus Rapid Transit (BRT) has been very effective in reducing pollution.

\section{Improving Urban Transit System Improves Urban Environment}

Evidences on emissions presented for the Kathmandu Valley (Table 5 and Table 6; Figure 6) suggest a need for immediate improvements. It would have been better to introduce a railway transit system in the Kathmandu Valley, but the immediate operation of a rail transit is not possible mainly due to the lack of physical (land) spaces. Given the existing road connectivity (Table 7), it might be best to introduce a Bus Rapid Transit (BRT) system for an immediate solution to reduce vehicular emissions. 
Table 7. Different types of roads serving the Kathmandu Valley.

\begin{tabular}{|c|c|c|c|c|c|c|}
\hline Jurisdiction & Classification & & Districts & & & \\
\hline & & Bhak-tapur & Kathmandu & Lalitpur & Total & Remarks \\
\hline \multirow{4}{*}{$\begin{array}{c}\text { Department } \\
\text { of Road } \\
(\mathrm{RoD})\end{array}$} & Highway & 14.1 & 39.9 & 18.0 & 72.0 & H02, H03, H16 \\
\hline & $\begin{array}{c}\text { Feeder Road } \\
\text { (Primary) }\end{array}$ & 70.5 & 136.0 & 112.6 & 319.0 & $\begin{array}{l}14 \text { Feeder } \\
\text { roads }\end{array}$ \\
\hline & $\begin{array}{l}\text { Feeder Road } \\
\text { (Secondary) }\end{array}$ & 27.0 & 45.1 & 0.0 & 72.1 & \multirow{2}{*}{$\begin{array}{l}22 \text { Feeder } \\
\text { roads } \\
59 \text { Feeder } \\
\text { roads }\end{array}$} \\
\hline & $\begin{array}{c}\text { Strategic Urban } \\
\text { Road }\end{array}$ & 4.9 & 59.6 & 27.2 & 91.7 & \\
\hline \multirow{5}{*}{$\begin{array}{c}\text { District } \\
\text { /Municipality }\end{array}$} & Total & 116.5 & 280.5 & 157.8 & 554.8 & \\
\hline & District Road & 36.0 & 400.4 & 90.6 & 527.0 & \\
\hline & Urban Road & 116.0 & 269.6 & 127.3 & 512.9 & \\
\hline & Total & 152.0 & 670.0 & 217.9 & 1039.9 & \\
\hline & Grand total & 268.5 & 950.5 & 375.7 & 1594.7 & \\
\hline
\end{tabular}

Source: DOR statistics of Strategic Road Network 2009/2010 H02: Tribhuvan Highway (4 lanes); H03: Arniko Highway (4 lanes); H16: Ring Road (2 lanes).

Traditionally, Kathmandu Valley was a pedestrian city, but in recent decades people of this Valley are served with the ring road and several radically linked feeder roads (Figure 4; Table 7). There are more vehicles that ply on the streets both at peak and off-peak hours (Table 1) in the Kathmandu Valley. Their numbers are increasing over time (Table 2) more than the length of road (Table 7) can sustain. The remittance economy that is contributing to the national GDP incrementally over the years, for example, 17 percent in 2007 [24], 23 percent in 2011 [26] [27], 29.97 percent in 2014 [28], and 30 percent in 2018 [25], has triggered the addition of many new vehicles in the Kathmandu Valley (Table 2). In western countries, the infatuation with private cars and wide roads is diminishing, and urban denizens are pleading for car-free compact cities. For examples, cities like Barcelona and Paris are transforming roads into car-free public spaces. However, the opposite is found in the Kathmandu Valley, which is already known for compact settlements. Paris has also come up with a concerted effort to reduce the number of private cars on its streets. Paris is slashing the number of lanes on major axes and redesigning seven major squares to reduce vehicle lanes and parking. The city plans to turn the neighborhoods into car-calmed, pedestrian- and bike-friendly zones with increased pedestrians space and greenery [29]. However, due to an unmanaged public transit system with uncertainties of reaching to destinations in the Kathmandu Valley, the number of motorcycles increased by 50 percent between 2009 and 2015. If the present trend continues, the number of motorcycle would increase by 49 percent between 2015 and 2034 (Table 2). In the Valley, various vehicles make around 5000 trips per day and it is expected that the trip would increase to 5456 per day by 2021 if the present trend of population growth in the Kathmandu Valley continues. It is projected 
that the intra-central trips would increase by 1.59 times and inter-city trips would increase by 1.62 times (Table 1). Assuming that the current trends of population growth (Table 2) and remittance propelled economy continue [24] [25] [26] [28], the number of both motorcycles and cars will increase exponentially, and their emissions would also increase (Table 5 and Table 6; Figure 6; Plate 2). If nothing is done to alleviate the current transit system of the Kathmandu Valley, after 10 - 15 years, every activity will be restricted due to severe traffic congestion, particularly along the central area inside the ring road (Figure 4). On the other hand, if the proposed outer ring road expansion becomes complete (Figure 7), it is certain that the level of mobility in 2021 onward will sustain the same existing level.

Proper management of public transit systems will improve the average vehicle speed during the peak hours from the existing level of $15 \mathrm{~km}$ per hour (kph) to $18 \mathrm{kph}$, and increase the average travel speed during off-peak hours from $25 \mathrm{kph}$ to $28 \mathrm{kph}$. The improvement of travel speed will also help in the reduction of pollution. A vehicle consumes the maximum gas when it is moving below the speed of $56 \mathrm{~km}$ (35 miles) per hour and above $113 \mathrm{~km}$ (70 miles) per hour in non-urban areas. A vehicle performs with maximum efficiency if it is within a speed range of between 56 - $112 \mathrm{~km}$ (35 - 69 miles) and emits less gas. Beyond those cutoff points, a vehicle would consume more gasoline and would emit more gases [56]. At present, many more motorcycles are added to the streets of Kathmandu Valley that are generating maximum amount of emission (Table 5

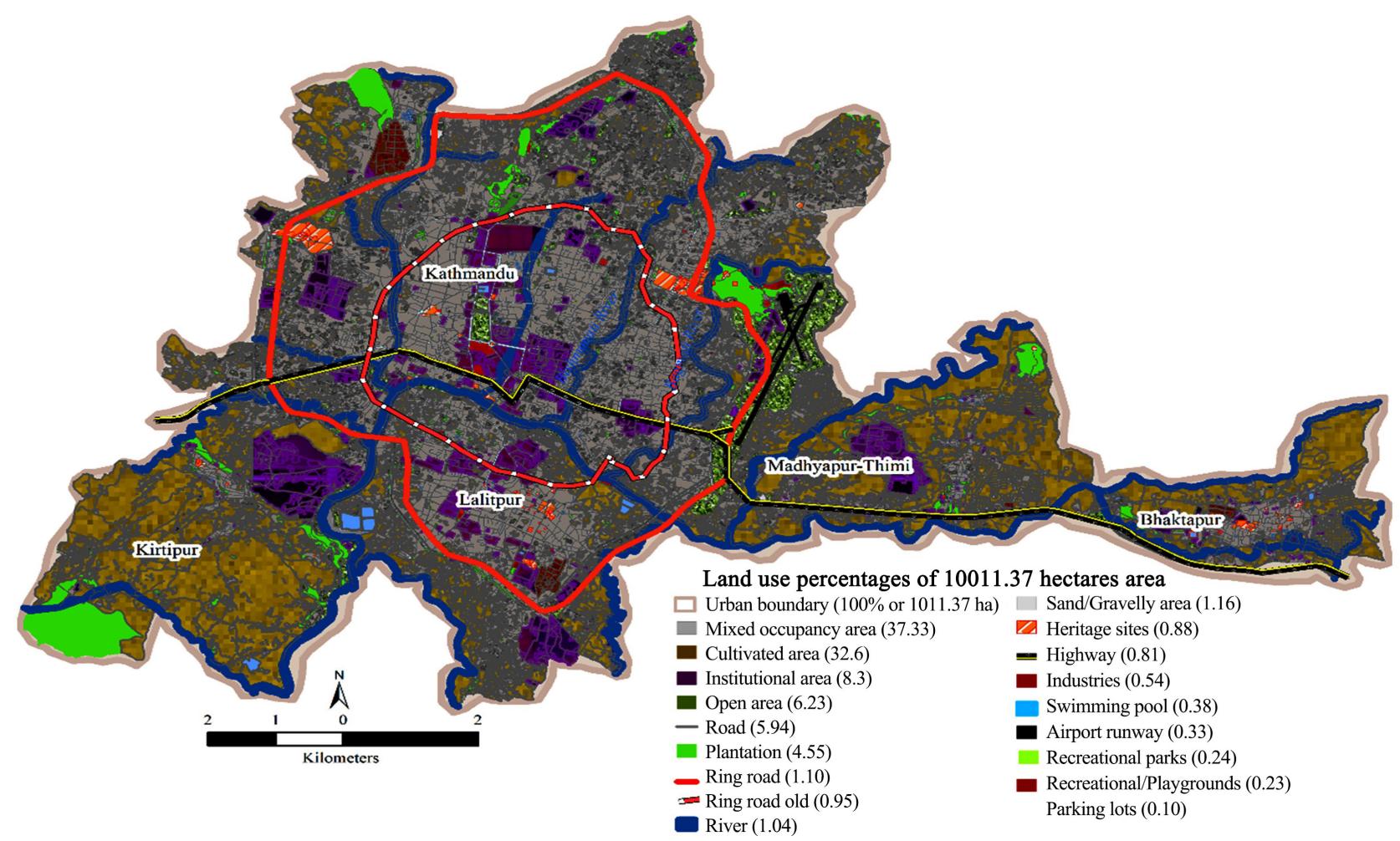

Figure 7. Existing and proposed ring roads of the Greater Kathmandu Valley. 
and Table 6). In the Kathmandu Valley, for immediate solution to ameliorate pollution, a Bus Rapid Transit (BRT) could be the feasible option. We propose to use prototype Transit-Tracker Apps to implement a good BRT system.

\subsection{How Apps Can Help Improve the Proposed BRT?}

According to urban literature, in France, in an average throughout a driving life, a vehicle driver spends about four years looking for a parking spot [57]. However, after the development of Apps, a person outright can reserve an available parking spot and save time looking for a parking place. Applying the similar analogy, in Nepal, we propose the use of prototype Transit-Tracker Apps to regulate the BRT system. A BRT system is a must for the Kathmandu Valley because in recent decades, unmanaged traffic not only has been problematic in balancing the work and family schedules among the Kathmandu denizens, but also holding off traffic on the road has created several environmental and accidental problems [31] [32]. Worldwide, accidents have become the eighth leading cause of death, killing 1.35 million people a year. This figure is higher than that of the deaths caused by malaria, HIV or tuberculosis [58]. More than half of the deaths are among vulnerable road users-pedestrians, cyclists, and motorcyclists. Some argue that the road expansion in the Kathmandu Valley was a blunder without necessary provisions to escape from the main road. Currently, many engineering students from various colleges of Nepal along with the transportation experts from China and Japan are conducting research to find the causes of road accidents in the Kathmandu Valley.

In 2009, the Asian Development Bank (ADB) suggested to have Primary, Secondary, and Tertiary routes, and replace the small buses and minibusses by fewer or larger buses. This was assumed to have substantially reduced the number of vehicles plying on the streets of Kathmandu and minimized the current emissions (Figure 6). By doing so, it would have reduced the cost of transportation per passenger with the decrease in the per capita gaseous emissions. Unfortunately, in the Kathmandu Valley, the location of bus stops are not marked clearly and most of the bus stops are not provided with minimum facilities such as shelters and bus bays; and no time table, route map and fare-rate have been made in public for the convenience of users. In the following paragraphs, we discuss the principles on how an App helps in tracking the Bus Rapid Transit (BRT).

The history of the Uber Apps technology is not that old at the global level. However, when it started, it soon became viral in over 600 cities of North Americas [59]. Individuals educated in the U. S. educational system have translated the Uber tracking technology to Nepal's geographic conditions in 2009. Since then many independent taxi drivers in the Kathmandu Valley are working on "on call" basis. Customers are advised to install on their smart phones, register, and feed information regarding the pickup and drop locations for taxis and motorcycles [59]. Recently, in Kathmandu, there are Kawa Rides, Sarathi Cab, 
Onver Smart Taxi, Eddy Cab and "Tootle Today" (a motorcycle ride sharing Apps). Users have been using these facilities with reliability and user-friendliness [59]. Motorcycle ride-sharing and taxi-hailing Apps have drawn the interest of the Kathmandu dwellers. Understandably, in the context of the Kathmandu Valley, these services are conceived to do away with problems faced by passengers. Unfortunately, taxis rarely run on meter, bargaining is the norm, taxi drivers reject a customer outright if the destination of the ride does not match with their liking and usually taxi drivers quote whatever number fancies them [59]. Even if these taxis and motorcycles provide services, these low occupancy vehicles generate many emissions. Thus, to improve the environmental conditions of the Kathmandu Valley, it would be worthwhile to start with the BRT system and use Transit Tracker Apps. Our proposed Transit Tracker Apps are based on the Haversine formula that uses the real-time information (RTI) on a geographic information system (GIS) platform.

The very first step of the Apps is the calculation of distances between different points. The Haversine formula is used to calculate the shortest distance using the great-circle distance (Figure 8) between two points over the earth's surface. It uses the "crow-flies" distance between the points, which obviously ignores the topography of the earth [18].

The great-circle distance or orthodromic distance is the shortest distance between two points measured along the surface of the sphere (as opposed to a straight line through the sphere's interior). The distance between two points in Euclidean space is the length of a straight line between them, but on the sphere, there are no straight lines. In spaces with curvature, straight lines are replaced by geodesics. Geodesics on the sphere are circles on the sphere whose centers coincide with the center of the spherical earth, and are called great circles [18]. The Great Circle distance is given by Equation (1)

$$
\begin{gathered}
a=\sin ^{2}\left(\Delta_{\varphi} / 2\right)+\cos \varphi_{1} \cos \varphi_{2} \sin ^{2}\left(\Delta_{\lambda} / 2\right) \\
c=2 \operatorname{atan} 2(\sqrt{a}, \sqrt{1-a}) \\
d=R c
\end{gathered}
$$

where, $\varphi$ is latitude in radian, $\lambda$ is longitude in radian, $R$ is earth's radius (mean radius $=6371 \mathrm{~km}-3960$ miles). The angle is measured in radians and trig functions are used to calculate the distances.

Our Transit-Tracker Apps use Java script and compute distances between different locations by converting geographic data (latitude and longitude) into the metric system, such as distance in miles $(\mathrm{ml})$ or in kilometers $(\mathrm{km})$ or in feet $(\mathrm{ft}$. or in meters $(\mathrm{m})$. Also, latitude and longitudinal values are used to find location-specific information, such as where a bus is, how is the traffic condition of that place, how far apart is the bus from the location of a waiting passenger, what is the condition of a road, and how long will it take for a bus to go to the subsequent multiple stations [60]. Such information can be quantified from Equation (2). 


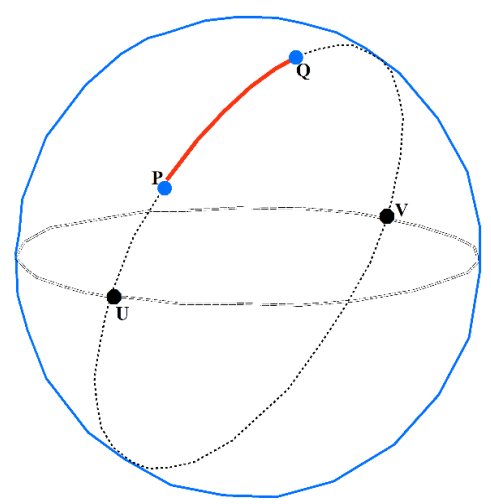

Figure 8. The hypothetical Great Circle distance on the earth. Great-circle distance (drawn in red) between two points on a sphere, $\mathrm{P}$ and $\mathrm{Q}$. Two antipodal points, $\mathrm{u}$ and $\mathrm{v}$, are also shown.

$$
\begin{aligned}
& \operatorname{var} \Delta \varphi=(\text { lat } 2-\text { lat } 1) \cdot \text { toRadians }() \text {; } \\
& \operatorname{var} \Delta \lambda=(\operatorname{lon} 2-\operatorname{lon} 1) \cdot \text { toRadians }() ; \\
& \text { vara }=\text { Math.sin }(\Delta \varphi / 2) * \text { Math } \cdot \sin (\Delta \varphi / 2) \\
& =\operatorname{Math} \cdot \sin (\Delta \varphi / 2) * \text { Math } \sin (\Delta \varphi / 2) \\
& * \text { Math.sin }(\Delta \lambda / 2) * \text { Math.sin }(\Delta \lambda / 2) \text {; } \\
& \operatorname{varc}=2 * \operatorname{Math} \cdot \operatorname{atan} 2(\operatorname{Math} \cdot s q r t(a) \cdot \text { Math.sqrt }(1-a)) \text {; } \\
& \text { vard }=R * C
\end{aligned}
$$

where,

" $\varphi$ " is latitude in radian,

" $\lambda$ " is longitude in radian,

"lat1," "lat2," "Ion1," "lon2" are latitudes and longitudes in degrees for various locations,

" $c$ " is the angular distance in radians, If atan2 is not available, $c$ could be calculated from $2^{\star}$ asin (min $(1, \sqrt{a})$ (including protection against rounding errors).

" $a$ " is the square of half the chord length between the points.

The Haversine formula is used to calculate distances between small and large-scales. A cell phone is capable of utilizing RTI and computing the distances efficiently. To calculate distances for a smaller area, the Spherical Law of Cosines method or Pythagoras Theorem are also useful.

In our programs, we have utilized JavaScript (Appendix A) with 64-bit floating-point numbers, which provide 15 significant figures of precision. These 15 significant figures of precisions are needed to calculate the exact distance between places in smaller areas. For example, our study area of the Kathmandu Valley is small where east-west extension is hardly 40 kilometers and north-south expansion is about 35 kilometers. Within such a short extent, many structures are built in an unplanned manner. In such unorganized urban area, it is truly hard to find the exact location without high precision. Thus, 15 
decimal places high precision are needed to pinpoint an exact location. For example, a popular spot can be tracked using values at the degree scale (60 minutes). One degree in Kathmandu is equivalent to $102.25 \mathrm{~km}$ - 102,250 meters (m) in horizontal extent. Likewise, one minute represents 1704.167 meters and one second represents 28.40278 meters. It is safer to use high precision point to locate any particular location. Our proposed Transit-Tracker Apps utilizing Spherical Law of Cosines formula $(\cos c=\cos a \cos b+\sin a \sin b)$ to calculate distances as small as few feet or meters. Calculation of such a precise distance requires a powerful smart phone. However, if a powerful smart phone becomes an issue, the Pythagoras Theorem can be used to compute distances for shorter routes. In using the Pythagoras Theorem, some accuracy might be compromised. No matter which algorithm is used, our proposed App utilize information of earth's major axis, minor axis, its flattening, and eccentricity factors to calculate the distances between locations with minimum error as given in Equation (3).

$$
\begin{gathered}
x=\Delta \lambda \cos \varphi_{m} \\
y=\Delta_{\varphi} \\
d=R \sqrt{x^{2}+y^{2}} \\
\text { var } x=(\lambda 2-\lambda 1) * \text { Math.cos }((\varphi 1+\varphi 2) / 2) ; \\
\text { var } y=(\varphi 2-\varphi 1) ; \\
\text { vard }=\text { Math.sqrt }(x * x+y * y) * R
\end{gathered}
$$

In order to check the wider applicability of our proposed Apps, we have tested Haversine modules for long and short distances, and the Spherical Law of Cosine and Pythagoras Theorem to compute shorter distances. These tested examples are presented in the Appendices A and B for all the four quadrants of the globe (Figure 3). These results justify that our proposed Apps are applicable for global, regional and local scales (Appendices B and C). Though several Apps are in use in Nepal, none is designed to track the RBT system as of today.

Four types of users can use our proposed Transit Tracker Apps. These users include: 1) Normal user; 2) Drivers; 3) Administrator(s); and 4) Sub-administrator(s). This application can be accessed by mobile application and web application.

\subsubsection{Normal Users}

Normal users are the basic users who use the Apps to track the location of a bus-arrival and departure time-at different locations, seats availability on the bus, conditions of roads, and stops over time per station. To be exact, normal users are the passengers who track the locations of a service providing bus that is plying on the service routes. These users utilize the proposed App (Figure 9(a)) on a mobile application and can see the list of buses available (Figure 9(b)). Users can click on the image of each bus, which will redirect them to the next page where they can see the current location of that particular bus.

Passengers can track the location of a bus (Figure 9(b)). The button, at the top right in the tracker, will open up a native map application and can help to track the exact path and distance between the passenger in waiting and the bus. 
A normal user may apply for any driver's position (Figure 10), if interested, when it is opened.

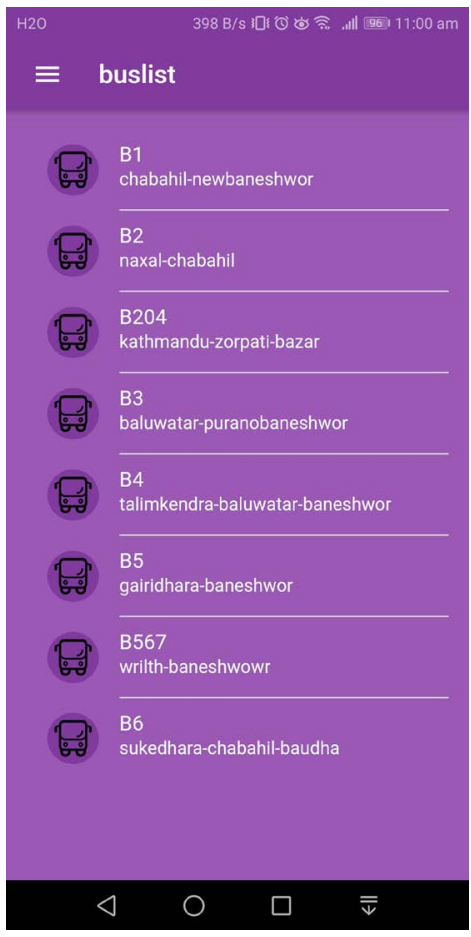

(a)

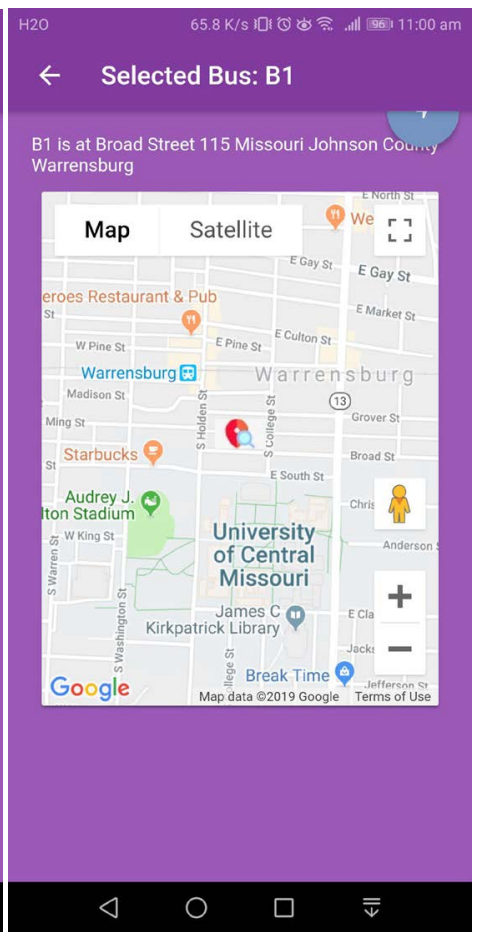

(b)

Figure 9. Opening of Transit-tracker and locating different buses. (a) Opening of Transit-tracker; (b) Locating different buses using RTI.

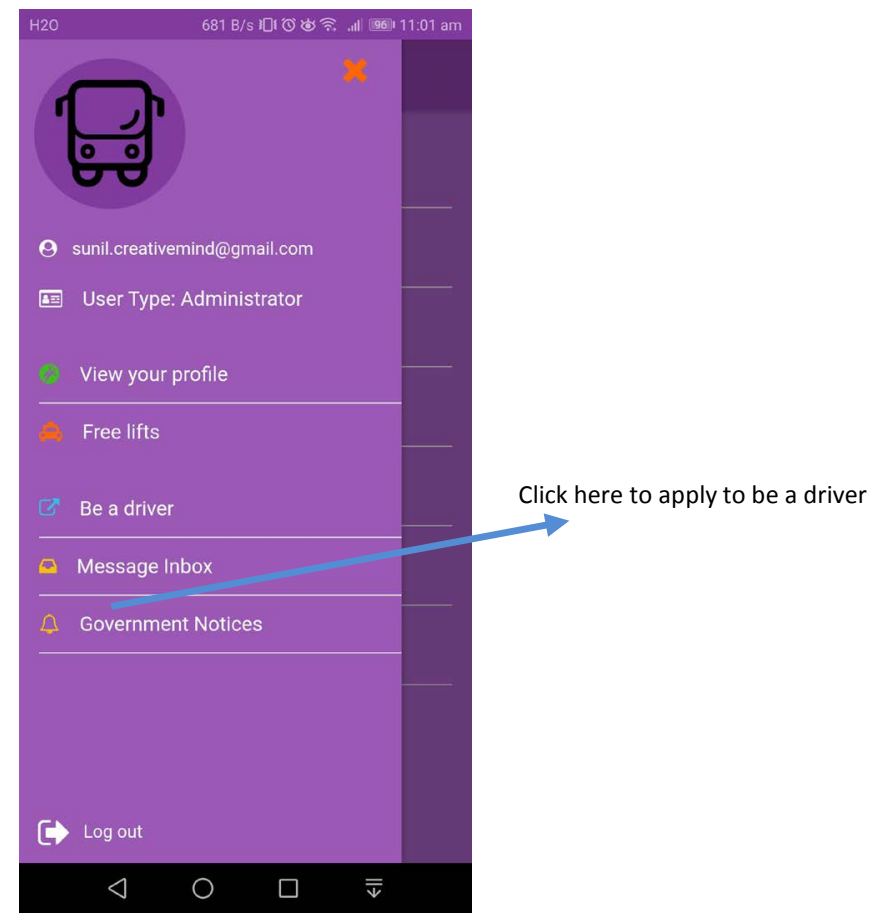

Figure 10. User can apply to be a driver. 
If applied for a driver's position, users can also check their inbox to see where their application status is or where this application is advancing from this point onward (Figure 11(a) and Figure 11(b)). The applicant can see the status of his/her application, such as a. Under review; b. Approved, but waiting for Admin approval; and c. Finally Approved (Figure 11).

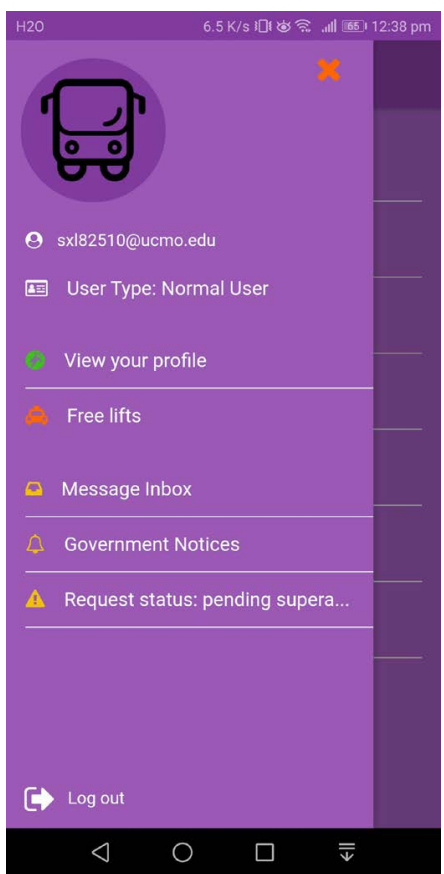

(a)

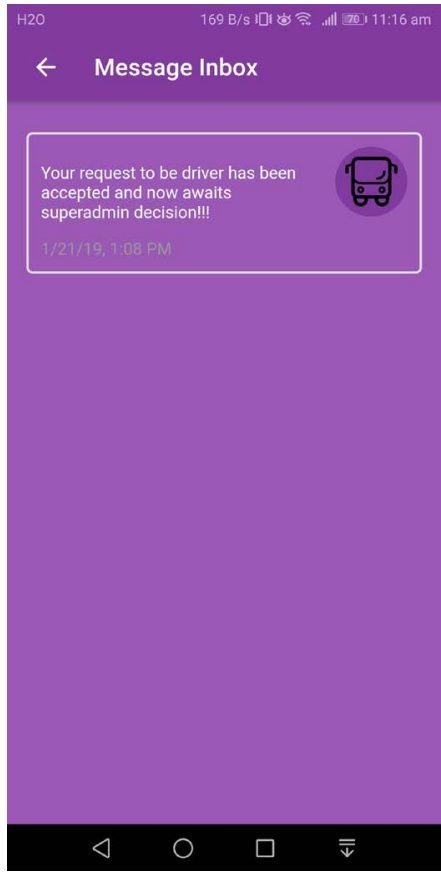

(b)

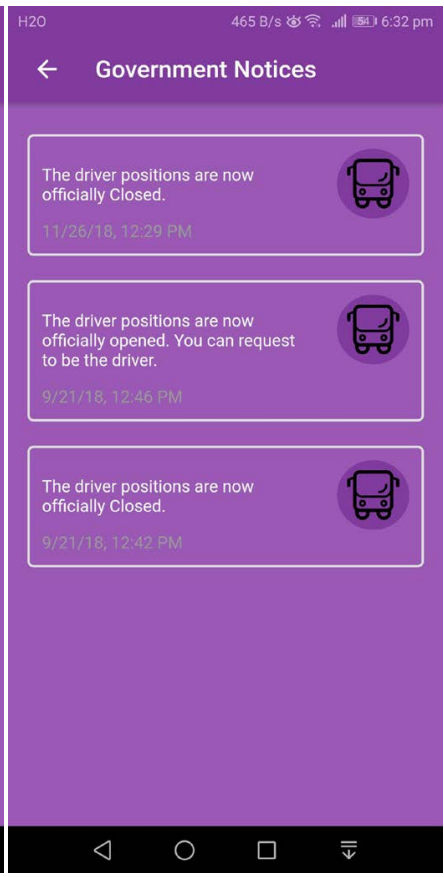

(c)

Figure 11. Processing applications. (a) Application under review; (b) Application waiting administrator's review; (c) Opening and closing of driver position. 


\subsubsection{Drivers}

Drivers are the users, who are assigned the status of a driver. A bus driver would use this application in his/her smartphone, and punch limited keys to send detailed information, such as the conditions of a bus, exact location of the bus, road and traffic conditions, environmental conditions, and seat availability for normal users including older adults.

\subsubsection{Administrator(s)}

An administrator controls many aspects of this proposed BRT. An administrator is responsible for looking into who to assign a driver's position and what matter needs to be directed to the sub-administrator. The administrator would direct a driver to take certain routes, avoid certain routes, and to reach a certain station within the designated period (Figures 12(a)-(b) and Figures 13(a)-(b)).

\subsubsection{Sub-Administrator(s)}

The application may be accepted or rejected at the sub-administrator's level. The sub-administrator would first verify the authenticity of the user by various

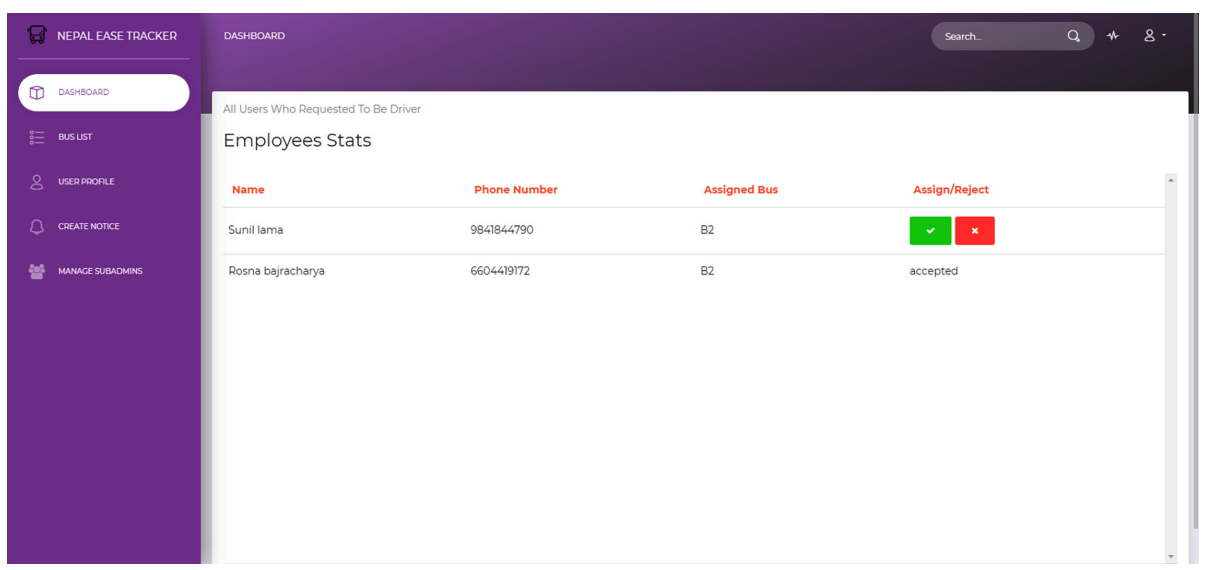

(a)

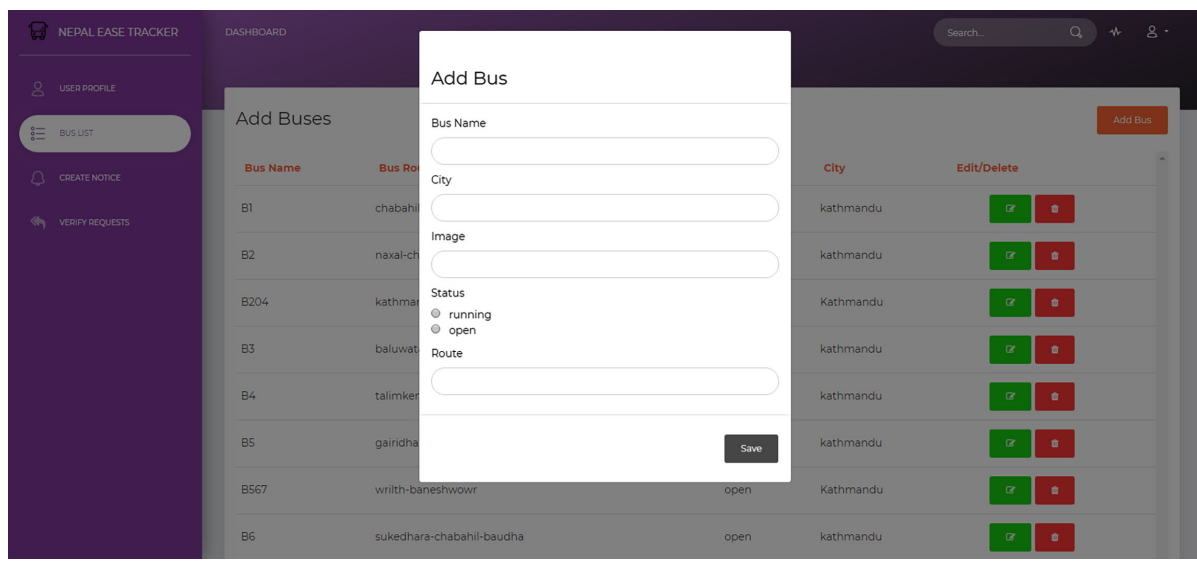

(b)

Figure 12. The figure 12 "a-b" shows how sub administrators and administrator interact. (a) Status of the application for driver's position (accept/reject); (b) Additional bus added to a certain route. 
Create notice for drivers

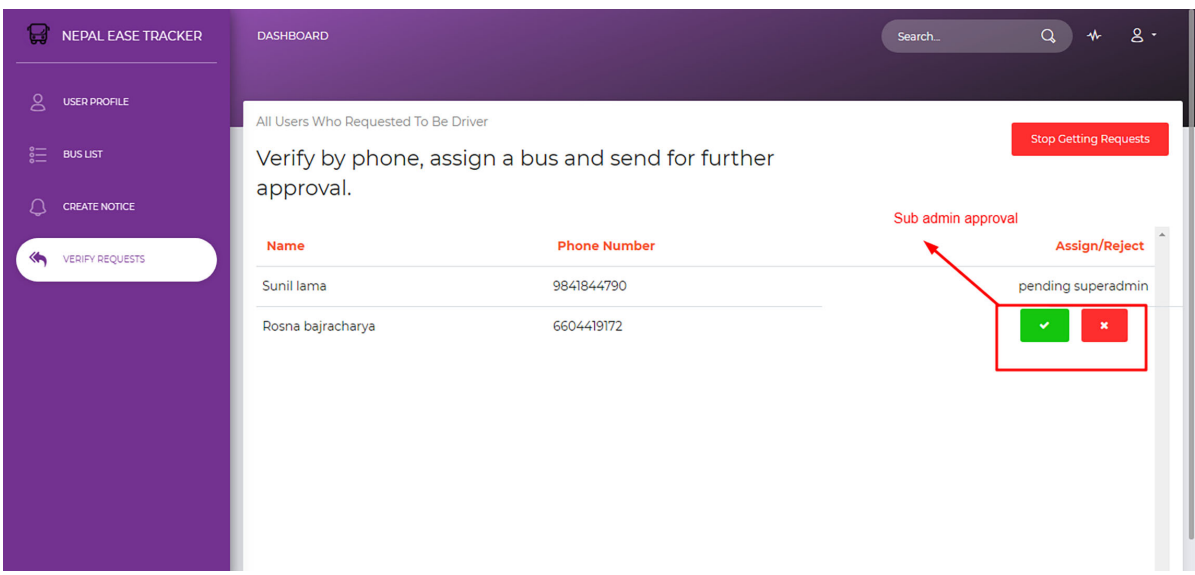

(a)

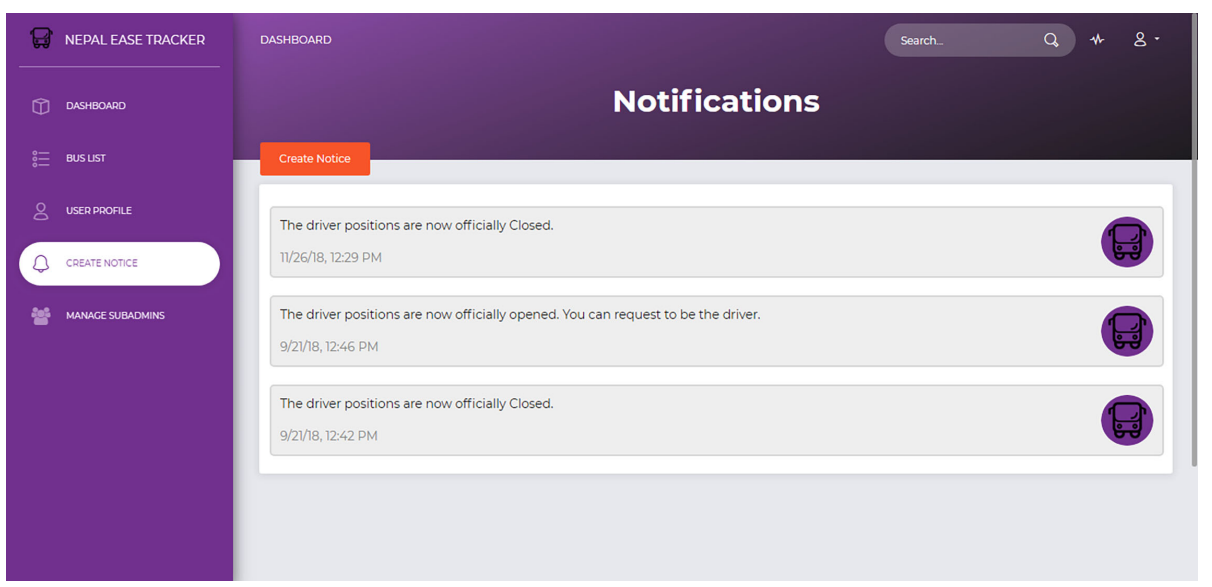

(b)

Figure 13. Creating a notice board. (a) Sub-administrator's portal; (b) Notification from sub-administrator.

means (phone call verifications for now, document checking manually) and then approve or disapprove for the driver position, which has to go through the administrator. This is to minimize any fraudulent characters that have to be filtered by the administrator itself. The sub-administrator would be able to add the new bus details, and publish new notices about the availability of driver's jobs from the web application. The Administrator may add a new bus service to a certain route (Figure 14(a)).

A sub-administrator issues government notices, such as opening positions for drivers, and forwarding received applications after scrutinizing all the necessary details. Sub-admins can also add and remove buses. The schematic diagram of the complete model is given in Figure 15.

\section{Ameliorating Vehicular Emission}

In order to operate the BRT in the Kathmandu Valley, we grouped the BRT transit operation in 5 steps (Figure 16). 


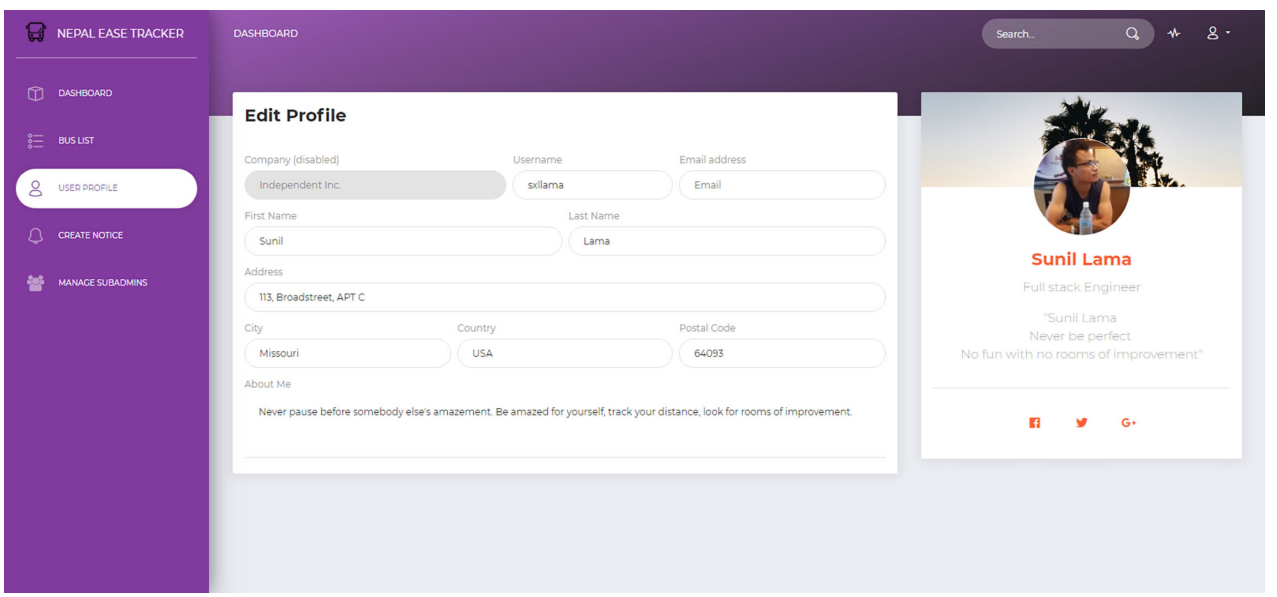

(a)

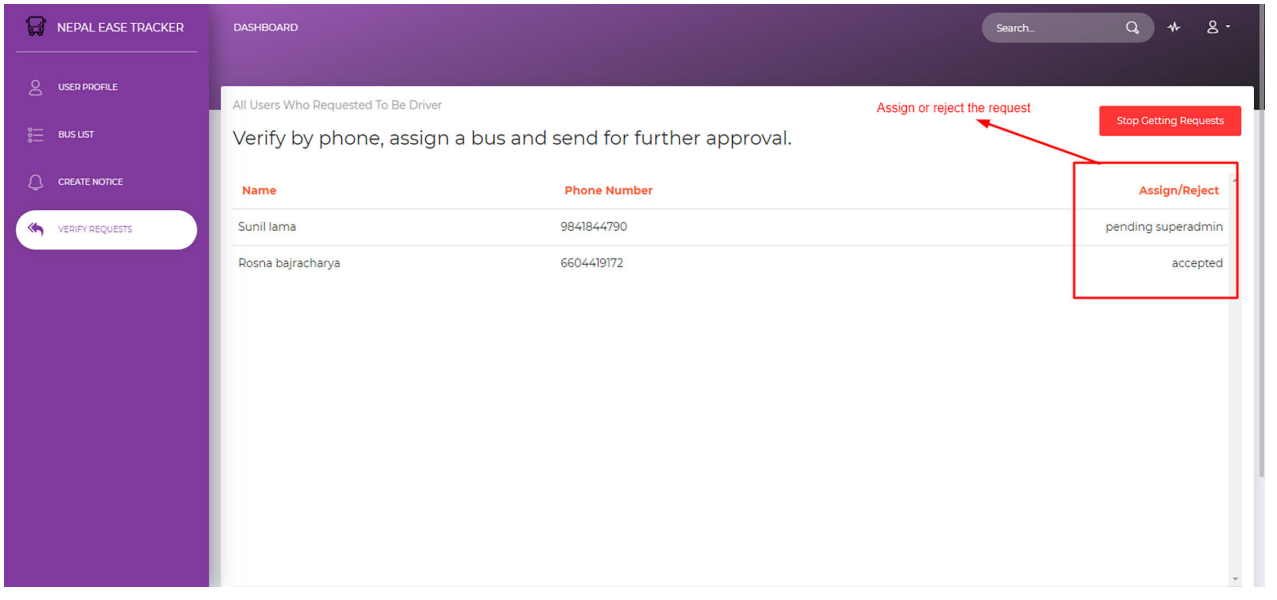

(b)

Figure 14. Sub-administrator portal to create notices. (a) Create a note for drivers; (b) Background check.

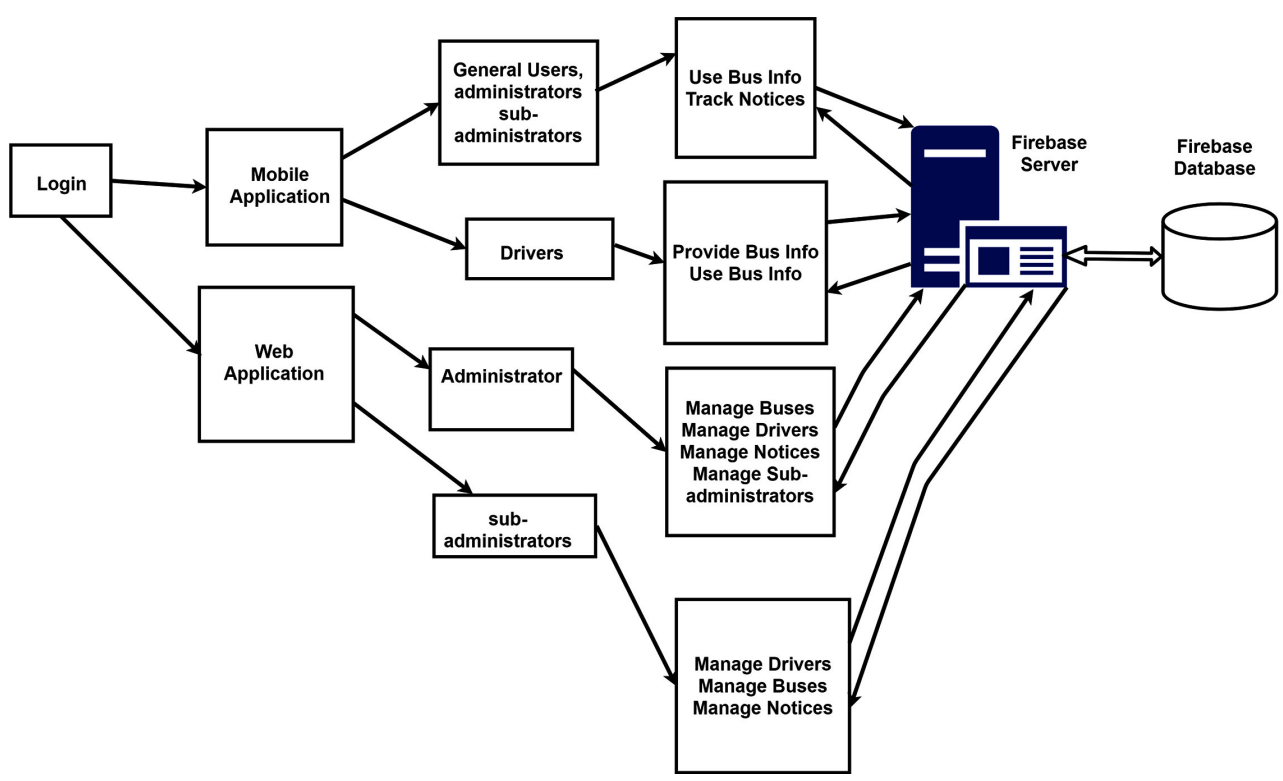

Figure 15. Complete model of a Transit-Tracker. 


\begin{tabular}{|c|c|c|c|c|}
\multicolumn{1}{c}{ Step 1 } & \multicolumn{1}{c}{ Step 2 } & Step 3 & Step 4 & Step 5 \\
\cline { 2 - 4 } $\begin{array}{c}\text { Identification of } \\
\begin{array}{c}\text { Stations (Table 9) } \\
\text { along the service } \\
\text { routes }\end{array}\end{array}$ & $\begin{array}{c}\text { Scheduling } \\
\text { departure and } \\
\text { arrival times of } \\
\text { buses at } \\
\text { different locations. }\end{array}$ & $\begin{array}{c}\text { Evaluations of } \\
\text { gaseous emission } \\
\text { levels from different } \\
\text { transit systems }\end{array}$ & $\begin{array}{c}\text { Reduction in } \\
\text { the number of } \\
\text { hospital visits } \\
\text { by patients. }\end{array}$ & $\begin{array}{c}\text { Wider applications } \\
\text { of the proposed } \\
\text { model to improve } \\
\text { urban transit } \\
\text { systems. . }\end{array}$ \\
\hline
\end{tabular}

Figure 16. The proposed BRT operating steps.

\subsection{Identifications of Bus Stations along the Roads in the Kathmandu Valley (Steps 1 and 2)}

For experimental purposes, we have identified 59 stations along the existing ring road and inner roads (only those inner roads where the operation of BRT is possible); marked the locations of bus stops, computed their latitudes and longitudes for each individual station, and computed distances between these locations using different formulae (Equations (1)-(3)). We also measured the distances among various stations using Google Earth. Additionally, we have also measured distances between different stations using a pedometer (walking) and a mileage reader (odometer) on motorcycles. The results of our computed distances are consistent with the ground verifications. These findings suggest that our proposed model is applicable both for large and small areas. Having observed consistent results from our approach, we developed schedules for the BRT (Appendix B). This schedule is based on the distance covered by a bus, anticipated traffic situations and road conditions based on real-time information (RTI). We hope that our proposed Transit-Tracker Apps would facilitate the operation of the BRT system that would ameliorate the environmental conditions of the Kathmandu Valley.

\subsection{The Effects of Proposed BRT System in the Kathmandu Valley (Steps 3 and 4)}

In the urban areas, a major factor of air pollution is due to vehicular emissions. An increasing number of vehicles and their emissions have increased the annual average level of total suspended particulate (TSP) matters $\left(\mathrm{PM}_{2.5}\right.$ and $\left.\mathrm{PM}_{10}\right)$ (Figure 17). Reduction of these particulates in the atmosphere could have positive impacts on public health.

An analysis of the emissions in 2009, 2015, 2021, 2025, 2031, and 2034 (Table 5 and Table 6; Figure 17) clearly indicate that the per capita annual $\mathrm{CO}_{2}$ emission differ for various vehicles. For example, Car-Taxi releases 6020 grams of $\mathrm{CO}_{2}$ whereas Mini-bus releases 1407 grams of $\mathrm{CO}_{2}$. Likewise, Micro-Bus releases 1772 grams of $\mathrm{CO}_{2}$ and Motor Cycle releases 3000 grams of $\mathrm{CO}_{2}$. The maximum amount of $\mathrm{CO}_{2}$ emission from a Car-Taxi is due to fewer people traveling by this transit system because of its expensive nature. The other high gas emitter is the Motor Cycle that fetches up to a maximum of two people per automobile. Low occupancy means higher per capita emissions per vehicle.

We argue that if high occupancy vehicles such as 35 - 40 seaters' bus replace low occupancy vehicles for example, a bus replacing 17 motorcycles, with strict 


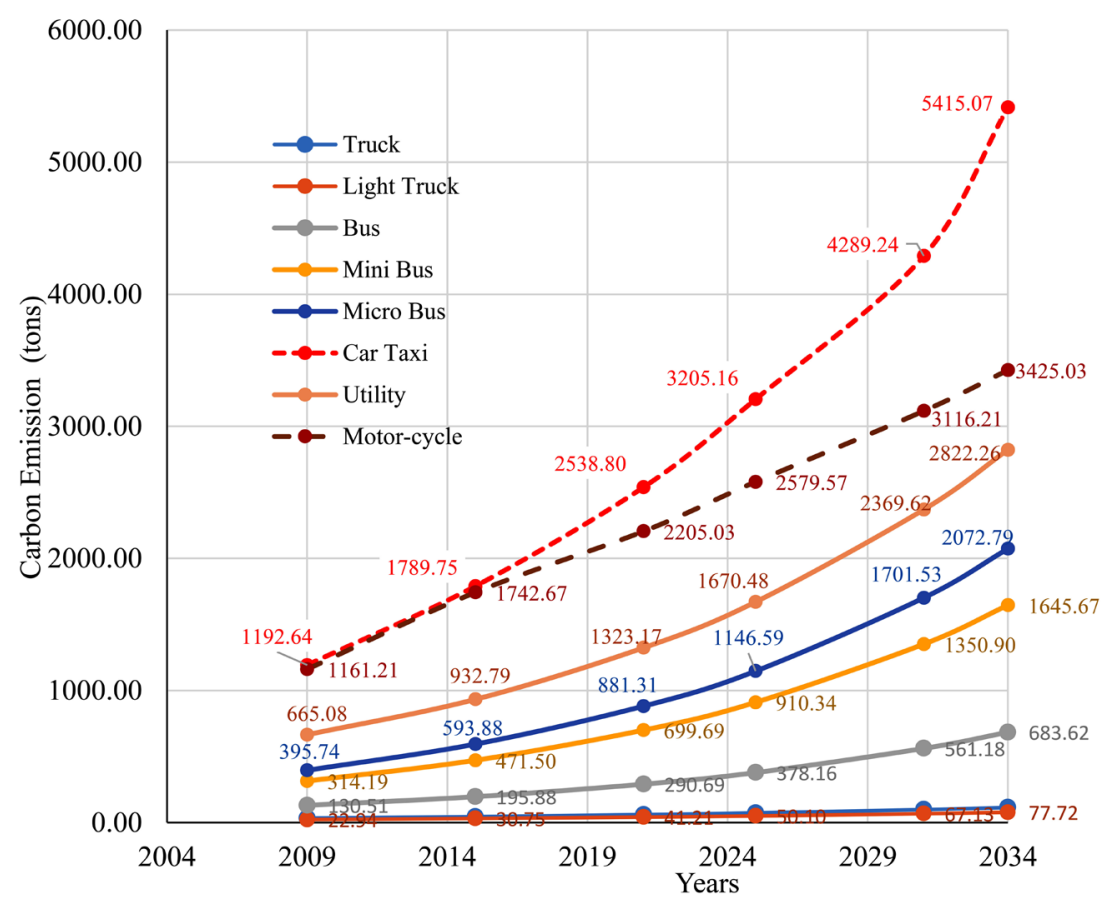

Figure 17. Emissions by various vehicles (2009-2034).

schedules and transit rules in the Kathmandu BRT system, the amount of emissions can be reduced to some extent (Figure 18). Table 2 shows that by 2021, almost 2,563,239 passengers would utilize public transit system and this number would increase to $3,216,351$ by 2025 , to $4,445,652$ passengers by 2031 , and to $5,316,149$ passengers by 2034 . In order to accommodate all these passengers (Table 2), we propose to increase the number of buses by 10.8 percent, but reduce the number of high per capita emission generating automobiles such as minibus by 4.87 , Micro-bus by 4.99 percent, car by 9.12 percent and motorcycle by 7.69 percent. We came to these percentages while meeting the transit needs for the number of passengers presented in Table 2. Our arguments are that high occupancy vehicles would help in the reduction of per capita emissions (Figure 18 and Figure 19) and thus, the transit system in the Kathmandu Valley would be effective by the Bus Rapid Transit (BRT) system.

Literature suggests that riding high occupancy public transit, when possible, becomes cost-effective and environmentally benign compared to riding low or single or few passenger vehicles. Riding a bus would reduce environmental pollutants per person than riding low occupancy vehicles. The fuel efficiency of a fully occupied bus is six times greater than that of the average single-occupant auto [61]. It would have been very cost effective if Nepal had a metro train; unfortunately, Nepal has to rely on a BRT for commuting because constructing a metro-rail or monorail is not feasible on a technical ground in the overly crowded urban area of the Kathmandu Valley that is seismically sensitive. Although the carbon emissions from the BRT system, especially, from buses jumps from 683 tons in the current stage (Figure 18) to 16,255 tons under BRT system 
(Figure 19), the overall $\mathrm{CO}_{2}$ emissions in the Kathmandu Valley decreases by 4000 tons per year (Figure 19). Thus, looking at the overall trends for now using a BRT would be the best choice to improve the environment and transit system in the Kathmandu Valley (Figure 19). Study by [62] revealed that a bus uses 8.7 percent less energy per passenger mile than a typical automobile such as motorcycle and/or car-taxi. If it were possible to have a train in the Kathmandu Valley, commuter trains would use 23.7 percent less energy per passenger for mile than a typical automobile. In terms of energy consumption per passenger mile (energy used to transport one passenger one mile), a BRT system is more energy efficient [62].

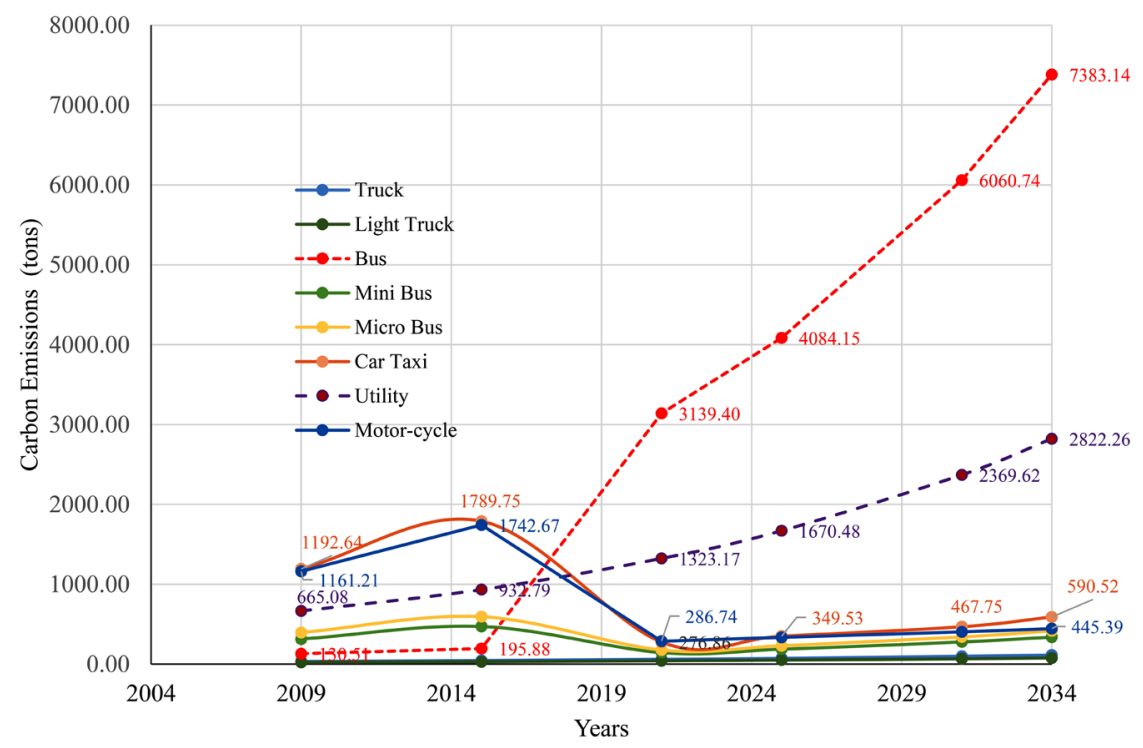

Figure 18. Projected gas emissions with a proposed BRT system.

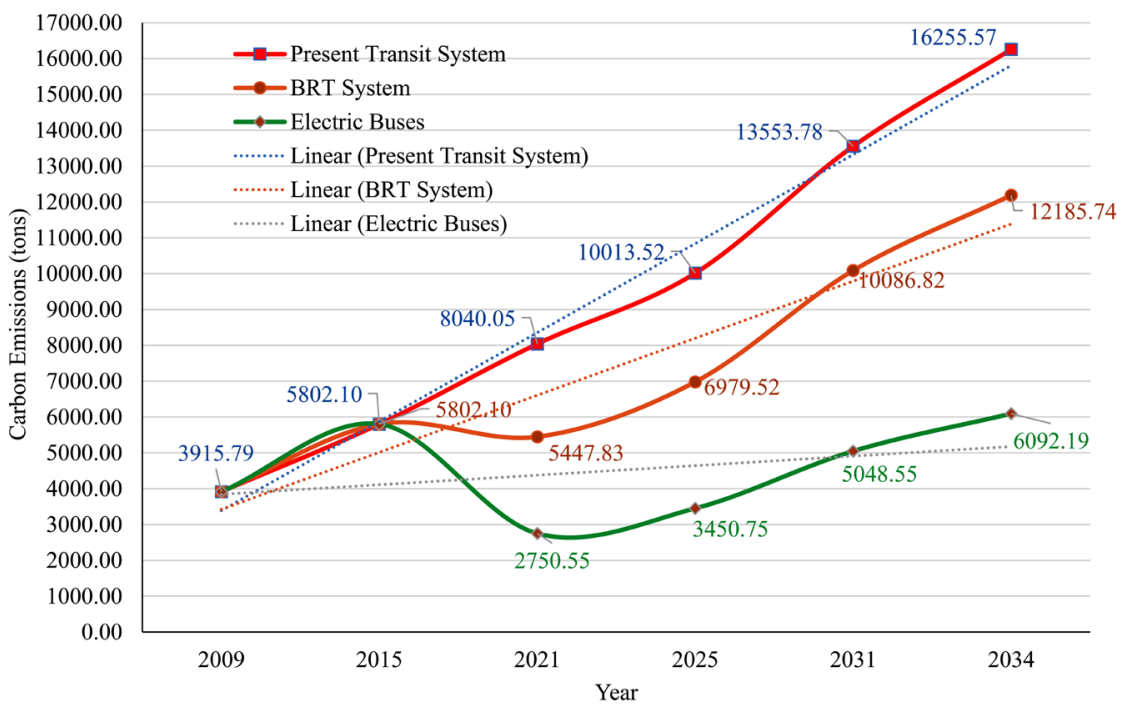

Figure 19. Emissions comparison between the current transit and the proposed BRT systems. The green line shows a hypothetical scenario if electric buses are used in the Kathmandu's transit system. 
A BRT public transit system can move people efficiently while producing significantly less air pollution to move one passenger per a mile-compared to moving a person one mile in a single-occupant auto. Buses emit only: 1) 20 percent of carbon monoxide per passenger mile as compared to a single-occupant auto; 2) 10 percent as much hydrocarbons per passenger mile as compared to a single-occupant auto; and 3) 75 percent as much nitrogen oxides (another ozone precursor) per passenger mile as compared to a single-occupant auto. Trains emit only 25 percent as many nitrogen oxides per passenger mile as a single-occupant auto, and nearly 100 percent less hydrocarbons and carbon monoxides. Clearly, riding a public transit throughout the year makes a big difference in air quality especially for those with health and breathing problems [63]. Thus, in order to keep Kathmandu relatively clean, it would be more worthwhile riding public buses than low occupancy vehicles. Additionally, only recently, the Government of Nepal has proposed the introduction of Electric Bus system in the Kathmandu Valley. Electric buses would reduce the emission by almost 50 percent [64].

The introduction of the proposed BRT system would help in the reduction of atmospheric particulates. Though our proposed approach might not lower the atmospheric particulates in the Kathmandu Valley to the level of international standards i.e. $50 \mathrm{mg} / \mathrm{m}^{3}$, implementation of this model might improve the environment of the Kathmandu Valley. If implemented properly, our approaches might contribute to the reduction in health costs and accidents as other researchers have argued for elsewhere, and also, specifically, for the Kathmandu Valley.

1) Under the changing scenarios, carbon emission will decrease by 32.2 percent in 2021 , by 30.3 percent in 2025 , by 25.6 percent in 2031 and by 25.09 percent in 2034. If electric buses are used, carbon dioxide emissions would be reduced by almost half the emissions of a diesel hybrid or a natural gas bus [64].

2) Reduce vehicular emissions by 10 - 15 percent per year [22] [65].

3) Reduce about 2000 hospital admissions per year because of the improvement in the environment [66];

4) Reduce 135,000 cases of acute bronchitis in children per year [20] [22];

5) Reduce 4000 cases of chronic bronchitis per year [20] [22];

6) Reduce half a million asthma attacks per year [22] [67]; and

7) Reduce the number of traffic accidents, which is around 30,000 per year [33] in the Kathmandu Valley.

Today, motorcycles and scooters are the major modes of transportation in Nepal in general, and in the Kathmandu Valley in particular. These low occupancy vehicles contribute more per capita emissions than by high occupancy vehicles. For example, a car on average generates 9.41 metric tons (1.882 metric ton/person assuming 5 persons per vehicle) of $\mathrm{CO}_{2}$ equivalent throughout the year, while a motorcycle generates 13.7 metric tons (6.85 metric ton/person 
assuming two persons per motorcycle) of $\mathrm{CO}_{2}$ [68]. Assuming that these transit modes are used regularly, about 3 - 4 hours a day in average. Riders use them very often because they have better gas mileage, readily available, and can pass through small spaces even during the time of traffic congestions. Unfortunately, they emit an excess of carbon monoxide (CO), nitrous oxides (NOx), and unburnt gas (HC's) which negatively affect human health. These emissions vary with the level of road surface roughness measured at the international roughness index (IRI) in meters per kilometer $(\mathrm{m} / \mathrm{km})$. The Highway Design and Maintenance Standards Model (HDM-4) [69] suggests that in an average, an IRI for the urban Kathmandu ranges between $4.0 \mathrm{~m} / \mathrm{km}$ and IRI 6.0/km, which is considered very high, major cause to emit high gaseous emissions. Therefore, Nepal needs a change in its transit system and must improve the conditions of roads.

\subsection{Countrywide Application of Prototype Transit Tracker [Step 5]}

With the promulgation of the new constitution in 2015, almost 65 percent of the total population of Nepal became urban dwellers. Overnight, the number of urban areas increased from 105 to 396 (276 municipalities, 11 sub-metropolises and 6 metropolises) (Figure 20) by annexing many of the adjacent rural areas. However, many of these urban areas so classified are characterized by rural opolises, yet, they wish to become "smart cities." These aspiring "smart cities" would need a well-planned urban transit system. Our proposed Transit-Tracker Apps would be instrumental in regulating transportation in many of the proposed smart cities throughout Nepal.

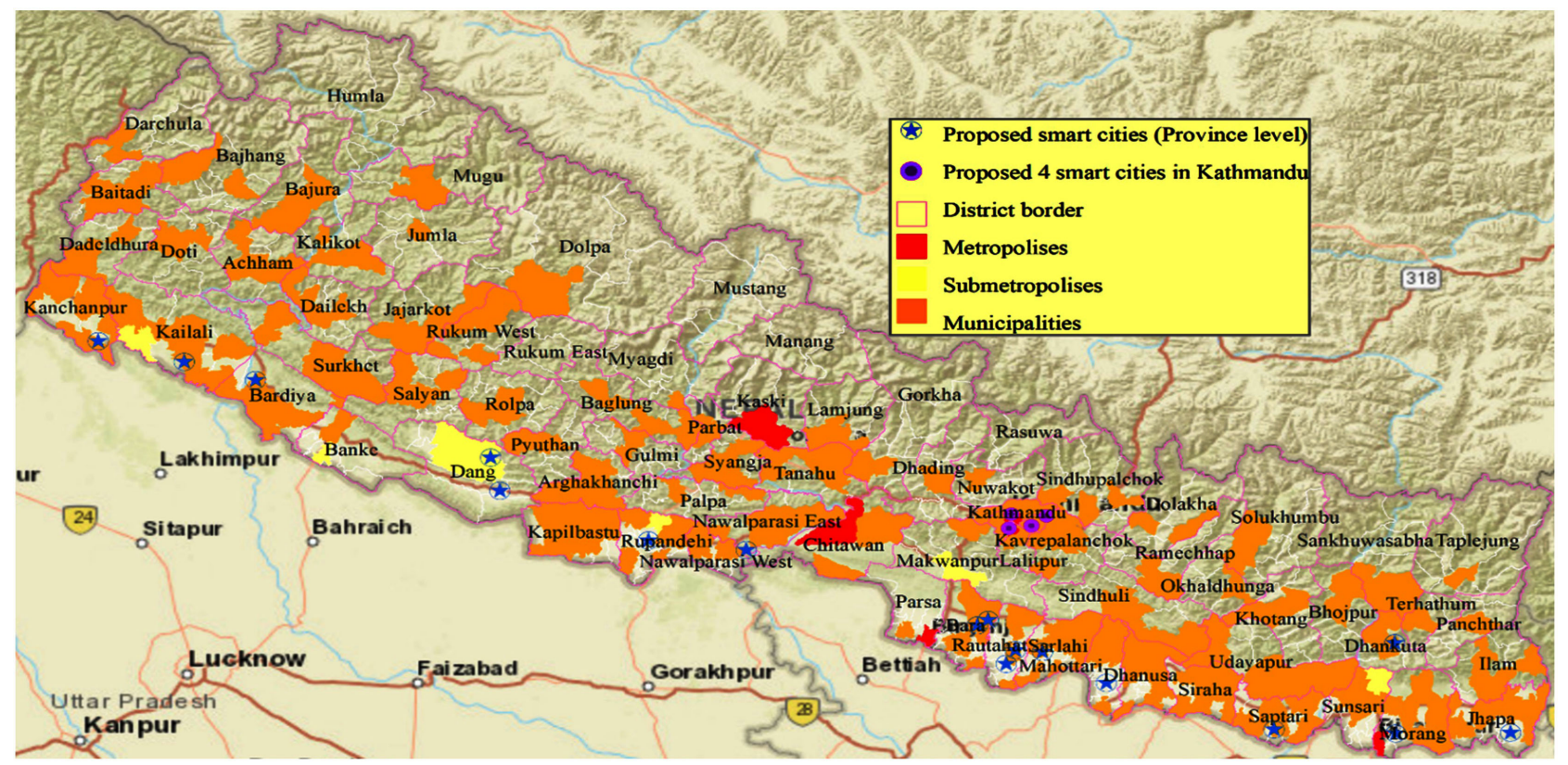

Figure 20. Urban area countrywide, proposed smart cities at the provincial level, 4 smart cities in the Kathmandu Valley, and other municipalities, sub-metropolis and metropolis. 
The concept of smart city embraces several definitions depending on the meanings of the word "smart": intelligent city, knowledge city, ubiquitous city, sustainable city, and digital city. Many definitions of a smart city have become viral, but not one has been universally acknowledged yet [70]. An effective transit system is one of the major components to making a "smart city" a success.

We argue that our proposed Transit-Tracker Apps will help to develop a well-organized Bus Rapid Transit (BRT) in many of the proposed 15 smart cities located in different parts of Nepal with one smart city in each province at metropolitan level and four proposed smart cities in the crowded Kathmandu Valley (Figure 1; Plate 3).

This Transit-Tracker will help in knowing the average speed, velocity, conditions of traffic, and arrival times to subsequent stations thus reducing the waiting times for passengers. Since many users are equipped with navigation devices, they will be able to utilize the real-time information (RTI) to track traffic conditions, for emergency services in accidents within the transportation network. Using the proposed Transit-Tracker, not only will help users to know their waiting times for the bus, but also it will guarantee the bus trips and bus-to-bus transfers with assured securities.

We expect that various investment agencies would be attracted to implement a BRT system in different smart cities of Nepal. We argue that our approach would benefit in saving travel time for users, lowering vehicle-operating costs (VOCs), improving safety and quality of public transit systems while minimizing repeated accidents.

\section{Discussion and Conclusion}

Air pollution stands as the fourth major factor for causing death worldwide leaving metabolic risks, dietary risks, and tobacco smoking behind, and 1 in 10 deaths is caused by air pollution [73]. Air pollution has great economic impact on health. At the global scale, $\$ 225$ billion is spent on the health sector to cure illness resulting from air pollution annually and South Asia has spent almost $\$ 66$ billion on health annually, which is approximately one percent of the Gross

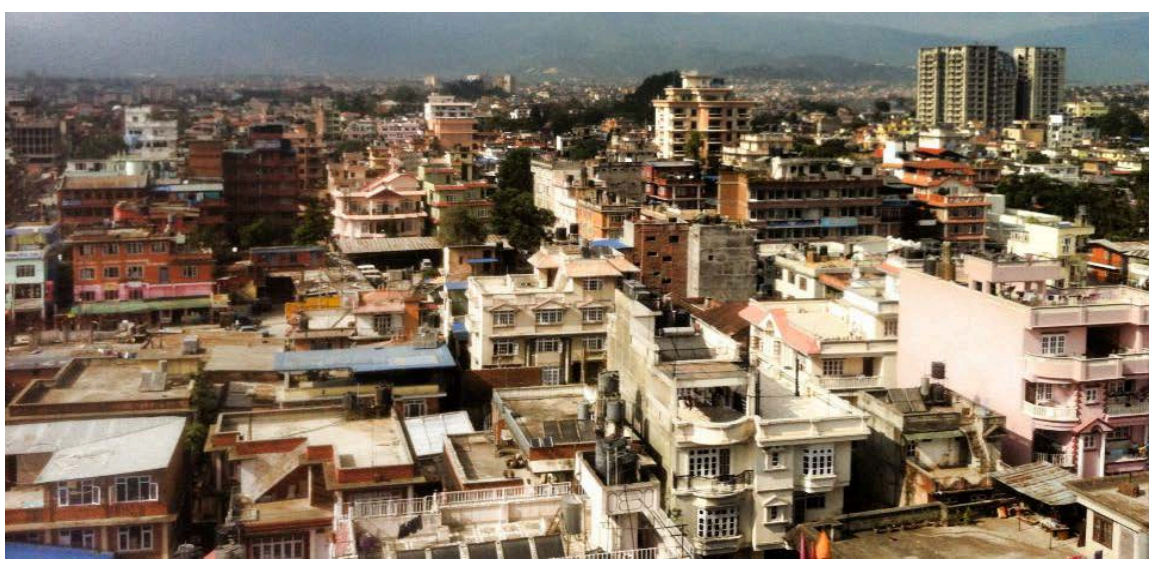

Plate 3. Crowded Kathmandu Valley [71]. Source: [72]. 
Domestic Product (GDP) [73]. At the global scale (Appendix C), approximately seven million people die each year due to breathing in fine particulate matters and it is the number one preventable cause of death [74]. Such preventable diseases can be controlled through the formulation of a government's environmental policy; revising and formulating national legislation; and by improving implementation practices, especially, in part of governance and coordination, and by establishing an effective monitoring system. $\mathrm{PM}_{2.5}$ caused an estimated $7 \cdot 6$ percent of total global mortality in 2015. In 2015, there were reports of 14 percent of preterm births being caused due to environmental pollution [75]. Further research revealed that in 2017, 2.7 - 3.4 million "preterm births" were associated with $\mathrm{PM}_{2.5}$ exposure [76]. In 2017, 12.6 million died due to environmental pollution of which air pollution alone killed over 7 million [41] [45] [46]. Every year, air pollution causes around 6.5 million premature deaths globally, of which, in house deaths account for 3.5 million and ambient air pollution deaths account for 3 million. By the 2040, annual premature deaths could go as high as 7.5 million [77]. Although global rates of mortality due to $\mathrm{PM}_{2.5}$ exposure decreased from 1990 to 2015 as a result of improved air quality in high-income countries [78]; Nepal's case is the complete reverse, especially, in the Kathmandu Valley.

According to the various surveys, almost 14 percent of the Kathmandu denizens lose their lives due to an excess of exposure to open air, 25.5 percent die because of chronic bronchitis, 12 percent suffer from restricted indoor activities because of no healthy recreational facilities to easily accessible areas, and 5.5 percent suffer from asthma [66]. If the concentration of $\mathrm{PM}_{2.5}$ is reduced to 58 $\mu \mathrm{mg} / \mathrm{m}^{3}$, Kathmandu's mortality may go down by 9 percent and hospital admissions may decrease by 29 percent, and if it is reduced to half $\left(44 \mu \mathrm{mg} / \mathrm{m}^{3}\right)$, Kathmandu's mortality can be reduced by 22 percent. This step would help in the reduction of $\$ 2.7$ million in health costs [66]. The Transit-Tracker model we proposed here is to overcome pollution problems and make the Kathmandu Valley's environment livable. This is possible because in recent years, both individual users and the perspective network managers can use cell phones and can navigate the location of buses to reduce their transit time and reach their destination on time even after they give up the use of low occupancy vehicles. Many more people are equipped with navigation devices that can track real-time traffic conditions of the network, emergencies or accidents [79].

A mobile application can simulate the traffic conditions through a routing algorithm that can help in projecting and detecting traffic jams by providing prior information. The proposed Transit-Tracker Apps will help to locate a bus, where it is parked, how long it takes to arrive at certain location, what bus would be best to use to reach certain location, in which station the user should make a change between different transport modes, and how to continue until the final destination. We argue that our App users would find it useful in their route choice decisions. The core aspects of this application are to: 1) use live traffic data and estimations of arc (distance) travel times in the future; 2) store users' preferences in their profiles; 3 ) suggest paths to the users and public transport 
modes; and 4) consider the users' preferences during the optimal path decision. Our proposed Apps would help establish an approach for mobile navigation in the Kathmandu Valley, but the caveat is the requirements of continuous data feed from different sources and a communication system between mobile phones and external servers. However, the intermittent internet services might cause problems.

Nepal needs drastic improvement in her urban transit system. With the current trend of internal migration and the trend of urbanization, over 70 percent of Nepali will live in urban areas by 2040 [41]. The number of vehicles is increasing in urban areas in every successive year. Currently, the concentration of Particulate Matter $\left(\mathrm{PM}_{2.5}\right)$ in urban areas of Nepal is more than 10 times higher than what WHO's [41] recommended level of $140 \mu \mathrm{g} / \mathrm{m}^{3}$. In 2012, the Ministry of Science and Technology of Nepal published guidelines on "National Ambient Air Quality (NAAQ).” The NAAQ's set standards for Nepal were still higher than that set by WHO [80]. Given the alarming level of particulate concentration in the atmosphere, the Department of Environment (DoE) has established environmental monitoring stations in nine different places, three stations within the Kathmandu Valley and six stations outside the valley, namely in Kavre, Pokhara, Chitwan and Rupandehi (http://pollution.gov.np) [81]. It was revealed from 24-hours observation that the average total suspended particles (TSP) in Kathmandu was $4749 \mu \mathrm{g} / \mathrm{m}^{3}, \mathrm{PM}_{10}$ was $2928 \mu \mathrm{g} / \mathrm{m}^{3}$, and $\mathrm{PM}_{2.5}$ was $226 \mu \mathrm{g} / \mathrm{m}^{3}$, which were much higher than WHO's recommended [82].

If this trend continues, by 2030, annual premature deaths in Nepal due to outdoor air pollution is expected to rise up to 24,000 [83]. The most alarming diseases will be due to respiratory illness, allergy, eye infection, lung cancer, chronic obstructive pulmonary disease (COPD), Ischaemic Heart Disease (IHD), and stroke [82]. Mortality from ambient air pollution obtained from the Global Health Observatory (GHO) for 2012 for Nepal shows 9944 deaths. Of these deaths, Ischaemic Heart Disease (IHD) deaths were 33.4 percent, 32 percent from stroke, 17.8 percent from chronic obstructive pulmonary disease (COPD), lung cancer was 9.3 percent, and Acute Lower Respiratory Tract Infection (ALRTI) was 7.4 percent. Females were in large number than males [46]. In 2013-2014, COPD was the most common (43 percent) cause of mortality among inpatients. Among the outpatients, the top fourth category disease was the respiratory tract (40 percent) with both upper and lower respiratory tract infections [84] and cancer (5 percent) [85]. District wise distribution within the valley showed that the highest number of patients from Kathmandu (44.4 percent), Lalitpur (10.3 percent), and Bhaktpur (10.2 percent). Many police officers who are involved in the regulations of traffic are exposed to different levels of air pollution. Traffic police who are being continuously exposed to dusty roads [86] [87] have their lungs seriously infected [88]. As of now, the Government of Nepal has made some attempts to address the environmental issues [81]. The Nepal government has been formulating policies to control environmental pollution since the 1990s, but the implementation of the legislation has not been effective 
enough. These include:

- the Environmental Act 1996 and Regulation 1997, National Climate;

- Change Policy 2011, National Low Carbon Economic Development Strategy, and the National Pollution Control Strategy and Action Plan;

- the National Transport Policy 2001, Transport Management Act 1992, Vehicles and Transport Management Rules 1998, and National Sustainable Transport Strategy (NSTS) 2015-2040;

- the Air Pollution Control Act for the Kathmandu Valley 2017;

- the High-Level Committee on Probing and Solving the Issues on 20-year-Old Vehicles, 2002;

- the Order of Supreme Court (2002) to Phase out of vehicles older than 20-year;

- the Vehicle Emission Standard and Monitoring Mechanism Act 2004; and

- the Technical Committee on the Relocation of Brick Industries from Kathmandu Valley 2004.

The Ambient Urban Air Quality Management program aims to bring the level of air pollution to the targeted level in the Kathmandu Valley within the next 5 years with the following approaches:

- Building an Environmentally Sustainable Transport System;

- Having Environment Friendly Construction Activities;

- Reducing the number of industries that emit polluting gases in the Valley;

- Promoting Cleaner Fuel and Technology to Minimize Domestic Pollution (Indoor Air Pollution).

The Metropolitan Traffic Police Division has directed schools and colleges in Kathmandu to carry schoolchildren before office hours. A simple approach such as carpooling has been encouraged to manage traffic generated by public offices [29]. Additionally, the government of Nepal is planning to improve the conditions of pilot routes, implement traffic management measures, pedestrianize heritage routes within the city center, and monitoring air quality in sensitive places. It is also hoped that such approaches would result in saving travel time for users, lower vehicle operating costs (VOCs), and improve in the safety and quality of the public transit system. The government intervention is essential because many of the urban transport services belong to private individuals or organizations and an improvement to the transport system will protect public welfare through a hygienic environment, and will prevent costs associated with negative externalities such as pollution and climate change [22].

Air pollution has been a huge burden to the residents of Kathmandu, threatening the lives of thousands of people of every year. It is likely that the scenario will be much worse in the coming years if immediate preventive measures are not taken on time. It is of utmost urgency to educate the common people on harmful aspects of air pollution and the necessary precautions to prevent its deadly consequences. The solution to Kathmandu's air pollution can be achieved only when the government takes stern actions to address the situation. The Con- 
stitution of Nepal 2015 has mentioned that a clean and healthy environment should be guaranteed to the people as their primary right. The National health policy of Nepal has included air pollution as a priority research/public health agenda, but the implementation has not been efficient. Benefit of doubt can be given to government as the political stability has been established and the government has made many tall promises to address pollution issues of the Kathmandu Valley in particular and all the urban areas throughout Nepal in general. We hope that the use of our proposed Apps using real-time would reduce passengers' waiting time for the bus, one of the most disliked elements of transit trips. It will also guarantee the bus trips and bus-to-bus transfers within the scheduled time. Many people in the Kathmandu Valley are transit-dependent and an improvement in the urban transit system would help them balance their home and work schedules.

We have examined the accuracies of our Apps at the global, regional, and local scales (Appendices B and C). Our results are matching with the ground reality. Though the formula ignores the curvature of the earth, calculating distances and estimating travel times to different locations make no difference, especially, for smaller areas like the Kathmandu Valley. In other words, our Apps have very high accuracy for local scales. Yet, we argue that our Apps will have universal applications because it is easy to locate popular places such as amusement park, historic sites, and public places even if the Apps show locations 10-15 meters away from such places. Our scheduling would work fine because each section of the road is identified with ground reality such as road length, speed limits, traffic conditions, and junctions with feeder roads. We believe that our proposed prototype Apps will enthuse scholars, investors, researchers, P-actors to advance transportation modeling in the Kathmandu Valley and later translating to countrywide to serve in all the proposed smart cities and other general routes. Our research described in depth the technical part and the disadvantages from the proposed Apps to start urban-transit planning.

\section{Limitation of the Research}

Though we have attempted to make the Apps perfect, we are now limited to the android mobiles; we are working on fine-tuning the iOS system. In this attempt, we have not perfected in addressing unreliable network, fuel shortage, poor infrastructure, roadblocks, traffic jams, and promotion and marketing in most cases, educating people about the use of apps for services demands time.

Despite their advantages, mobile navigation systems suffer from several drawbacks such as intermittent internet services. The purpose of this article is not to describe in depth the technical part of each application and their disadvantages, but to provide a starting point for urban planning using androids. In the future, we plan to undertake surveys of public transport systems to gather information on total traffic, its composition (number of buses) and vehicle occupancy, the prevailing average vehicle speed, steps needed to improve public 
transportation and traffic management. Presently only android users can benefit from their services. Use of smartphones by users accompanied by their familiarity with, digital mapping with internet would help large number of users.

In our next step, we not only plan to measure distances from point to point, but also, we are planning to start-up through a baseline survey to quantify other real benefits of the project, such as time savings, accident reduction, carbon dioxide emissions reduction, air quality improvement, walkability improvement, noise reduction (with electric vehicles), and improved travel reliability. Since the government of Nepal has recently mulling to buy 300 electric buses, we expect a tremendous improvement in the traffic system of the Kathmandu Valley. Testing the usefulness of the Transit-Tracker Apps would be a win-win situation for academia, the public, and the government. Transit entrepreneurs also will find this application promising for investments in transit systems.

\section{Conflicts of Interest}

The authors declare no conflicts of interest regarding the publication of this paper.

\section{References}

[1] Yue, W.S., Hoy, C.W. and Chye, K.K. (2017) A Preliminary Survey Analysis of School Shuttle Bus System towards Smart Mobility Solutions. AIP Conference Proceedings, 1891, Article ID: 020146. https://doi.org/10.1063/1.5005479

[2] World Atlas (2017) The World Atlas Best of 2017. https://www.worldatlas.com/articles/the-world-atlas-best-of-2017.html

[3] Gurung, J. and Lama, A.K. (2017) Nature Tourism. MyRepublica. https://myrepublica.nagariknetwork.com/news/20484/

[4] Neff, J. and Dickens, M. (2016) Public Transportation Fact Book. American Public Transportation Association, Washington DC.

[5] Texas A\&M Transportation Institute (2012) TTI’s 2012 Urban Mobility Report. https://assets.documentcloud.org/documents/566377/2012-urban-mobility-report.p df

[6] Brakewood, C., Barbeau, S. and Watkins, K. (2014) An Experiment Evaluating the Impacts of Real-Time Transit Information on Bus Riders in Tampa, Florida. Transportation Research Part A: Policy and Practice, 69, 409-422. https://doi.org/10.1016/j.tra.2014.09.003

[7] Walker, J. (2014) Human Transit. Island Press, Washington DC.

[8] Carrel, A., Halvorsen, A. and Walker, J. (2013) Passengers' Perception of and Behavioural Adaptation to Unreliability in Public Transportation. Transportation Research Record: Journal of the Transportation Research Board, 2351, 153-162. https://doi.org/10.3141/2351-17

[9] Schweiger, C. (2011) Use and Deployment of Mobile Device Technology for Real-Time Transit Information. Transportation Research Board, Washington DC.

[10] Levinson, H.S., Zimmerman, S., Clinger, J., Harris, D.M.J.M. and Rutherford, C.S. (2002) Bus Rapid Transit: AN Overview. Journal of Public Transportation, 5, 1-30. https://doi.org/10.5038/2375-0901.5.2.1 
[11] Harrington, P., Kelker, R. F. and DeLeuw, C.E. (1937) A Comprehensive Local Transportation Plan for the City of Chicago.

[12] Mass Transportation Survey (1959) National Capital Region, Civil Engineering Report. DeLeuw Cather \& Co., January.

https://www.enotrans.org/etl-material/1959-national-capital-region-mass-transport ation-survey/

[13] W. C. Gilman \& Co. (1959) St. Louis Metropolitan Area Transportation Study. Prepared for the City of St. Louis and St. Louis County, August.

[14] Barton-Aschman Associates (1971) Milwaukee Area Transit Plan: A Mass Transit Technical Study. June 1971.

[15] Zhang, F., Shen, Q. and Clifton, K.J. (2008) Examination of Traveler Responses to Real-Time Information about Bus Arrivals Using Panel Data. Transportation Research Record: Journal of the Transportation Research Board, 2082, 107-115. https://doi.org/10.3141/2082-13

[16] Ferris, B., Watkins, K. and Borning, A. (2010) OneBusAway: Results from Providing Real-Time Arrival Information for Public Transit. Proceedings of the SIGCHI Conference on Human Factors in Computing Systems, Atlanta, Georgia, 10-15 April 2010, 1807-1816. https://doi.org/10.1145/1753326.1753597

[17] Gooze, A., Watkins, K.E. and Borning, A. (2013) Benefits of Real-Time Transit Information and Impacts of Data Accuracy on Rider Experience. Transportation Research Record: Journal of the Transportation Research Board, 2351, 95-103. https://doi.org/10.3141/2351-11

[18] Dale, P. (2005) Introduction to Mathematical Techniques Used in GIS. CRC Press, Boca Raton.

[19] Panday, A.K. and Prinn, R.G. (2009) Diurnal Cycle of Air Pollution in the Kathmandu Valley, Nepal: Observations. Journal of Geophysical Research: Atmospheres, 114, D09305. https://doi.org/10.1029/2008JD009777

[20] Saud, B. and Paudel, G. (2018) The Threat of Ambient Air Pollution in Kathmandu, Nepal. Journal of Environmental and Public Health, 2018, Article ID: 1504591. https://doi.org/10.1155/2018/1504591

[21] Parajuly, K. (2016) Clean up the Air in Kathmandu. Nature, 533, 321. https://doi.org/10.1038/533321e

[22] CANN (2014) Clean Energy Nepal. Air Quality Status and Management in Kathmandu Valley. Clean Air Network Nepal (CANN).

http://www.cen.org.np/uploaded/AQ\%20Status\%20and\%20Managment\%20in\%20 KV_Maya\%20Factsheet\%205.pdf

[23] Regmi, R.P., Kitada, T. and Kurata, G. (2003) Numerical Simulation of Late Wintertime Local Flows in Kathmandu Valley, Nepal: Implication for Air Pollution Transport. Journal of Applied Meteorology and Climatology, 42, 404-416. https://doi.org/10.1175/1520-0450(2003)042<0389:NSOLWL >2.0.CO;2

[24] Mahat, J.J. (2019) Remittance Economy and Nepal. Business $360^{\circ}$. https://www.b360nepal.com/innovation/remittance-economy-and-nepal.html

[25] Nepal Economy (2018) Economy Overview. Nepal Economy 2018. CIA World Factbook and Other Sources. https://theodora.com/wfbcurrent/nepal/nepal_economy.html

[26] World Bank (2011) Migration and Remittances Fact Book. World Bank, Washington DC.

[27] World Bank (2012) World Bank Brief on Global Migration and Remittances. World 
Bank, Washington DC.

[28] Xinhua (2014) Contribution of Remittance to GDP Reaches 25 Percent. Xinhua. http://www.globaltimes.cn/content/866600.shtml

[29] Joshi, K. (2019) Road Widening in the Kathmandu Valley-What Is the Point? Architecture Category Article.

https://spacesnepal.net/2017/05/12/road-widening-in-the-kathmandu-valley-whatsthe-point/?fbclid=IwAR18gACO1pWpYFbvP81Xuz56P8PInNMDKZEl3g2Xb6h_O -AUFfI1L6Yi6Jo

[30] Bhattarai, K. and Conway, D. (2010) Urban Vulnerabilities in the Kathmandu Valley, Nepal: Visualizations of Human/Hazard Interactions. Journal of Geographic Information System, 2, 63-84. https://doi.org/10.4236/jgis.2010.22012

[31] Bhattarai, K. (2015) Bright Lights, Big Cities. The Kathmandu Post. http://kathmandupost.ekantipur.com/printedition/news/2015-02-09/bright-lights-b ig-cities.html

[32] Bhattarai, K. (2018) Managing Urban Traffic. MyRepublica. https://myrepublica.nagariknetwork.com/news/managing-urban-traffic/

[33] Shrestha, A. (2018) Kathmandu's Roads Are Widening, but There's No Space for Pedestrians. The Kathmandu Post.

http://kathmandupost.ekantipur.com/news/2018-12-22/kathmandus-roads-are-wid ening-but-theres-no-space-for-pedestrians.html

[34] Burathoki, V. (2018) Professor at Nepal Engineering College, Specialist in City Development. In: Shrestha, A., Ed., Kathmandu's Roads Are Widening, but There's No Space for Pedestrians.

[35] Sharma, B. (2019) Urban Sprawl Turns 172 Petrol Pumps in Kathmandu Valley into Safety Hazards. MyRepublica.

https://myrepublica.nagariknetwork.com/news/urban-sprawl-turns-172-petrol-pu mps-in-kathmandu-valley-into-safety-hazards/

[36] WWTG.Com (2018) Air Pollution in Kathmandu-What You Should Know. World-Weather-Travellers-Guide.com. https://www.world-weather-travellers-guide.com/air-pollution-in-kathmandu.html

[37] Clean Energy Nepal (2014) Renewable Energy Powers Rural Nepal into the Future. http://www.worldbank.org/en/news/feature/2014/02/05/renewable-energy-powers-r ural-nepal-into-the-future

[38] MSTE (2014) Ministry of Science, Technology and Environment. Government of Nepal.

[39] Thapa, G. and Adhikari, A.K. (2016) Kathmandu: The Third Most Polluted City in the World. The Kathmandu Post.

http://kathmandupost.ekantipur.com/news/2016-03-19/kathmandu-the-third-most -polluted-city-in-the-world.html

[40] Numbeo.Com (2016) Pollution in Kathmandu, Nepal. https://www.numbeo.com/pollution/in/Kathmandu

[41] WHO. World Health Organization (2017) Nepal Urban Health Profile. http://www.who.int/kobe_centre/measuring/urbanheart/nepal.pdf

[42] CDC (2017) Air Quality. Particle Pollution. Centers of Disease Control and Prevention (CDC). https://www.cdc.gov/air/particulate_matter.html

[43] Gautam, D.R. (2015) Air Pollution: Its Causes and Consequences With Reference To Kathmandu Metropolitan City. The Third Pole: Journal of Geography Education, 8, 27-33. https://doi.org/10.3126/ttp.v8i0.11509 
[44] Xing, Y.F., Xu, Y.H., Shi, M.H. and Lian, Y.X. (2016) The Impact of PM2.5 on the Human Respiratory System. Journal of Thoracic Disease, 8, E69-E74.

[45] WHO. World Health Organization (2017) Air Pollution. http://www.who.int/topics/air_pollution/en

[46] WHO. World Health Organization (2017) An Estimated 12.6 Million Deaths Each Year Are Attributable to Unhealthy Environments. Media Center. http://www.who.int/mediacentre/news/releases/2016/deaths-attributable-to-unhealt hy-environments/en/

[47] Li, Z., Bian, X., Yin, J., Zhang, X. and Mu, G. (2016) The Effect of Air Pollution on the Occurrence of Nonspecific Conjunctivitis. Journal of Ophthalmology, 2016, Article ID: 3628762. https://doi.org/10.1155/2016/3628762

[48] Wang, Y., Kloog, I., Coull, B.A., Kosheleva, A., Zanobetti, A. and Schwartz, J.D. (2016) Estimating Causal Effects of Long-Term PM2.5 Exposure on Mortality in New Jersey. Environmental Health Perspectives, 124, 1182-1188. https://doi.org/10.1289/ehp.1409671

[49] Crouse, D.L., Peters, P.A. and Hystad, P. (2015) Ambient $\mathrm{PM}_{2.5}, \mathrm{O}_{3}$, and $\mathrm{NO}_{2}$ Exposures and Associations with Mortality over 16 Years of Follow-Up in the Canadian Census Health and Environment Cohort (CanCHEC). Environmental Health Perspectives, 123, 1180-1186. https://doi.org/10.1289/ehp.1409276

[50] Beelen, R., Raaschou-Nielsen, O. and Stafoggia, M. (2014) Effects of Long-Term Exposure to Air Pollution on Natural-Cause Mortality: An Analysis of 22 European Cohorts within the Multicentre ESCAPE Project. The Lancet, 383, 785-795. https://doi.org/10.1016/S0140-6736(13)62158-3

[51] AFP (2017) Bus Mafia Controlling Nepal's Smog-Choked Capital. https://www.geo.tv/latest/138336-Bus-mafia-controlling-Nepals-smog-choked-capit al

[52] Shresthat, N.R. and Bhattarai, K. (2017) Historical Dictionary of Nepal. 2nd Edition, Rowman \& Littlefiel. Lanham. Bouler, New York, London.

[53] Dixit, H. (2017) Getting-Around-Kathmandu. Spotlight, 10. https://www.spotlightnepal.com/2017/03/09/getting-around-kathmandu/

[54] DUDBC (2018) Department of Urban Development and Building Construction. Ministry of Urban Development. Government of Nepal. http://dudbc.gov.np/

[55] Trading Economics (2019) Nepal Corruption Rank. https://tradingeconomics.com/nepal/corruption-rank

[56] Black, W.R. and Nijkamp, P. (2002) Social Change and Sustainable Transport. Barnes and Noble, New York.

[57] Bhattarai, K. (2018) Nepal's Smart City Dream. MyRepublica. https://myrepublica.nagariknetwork.com/news/nepals-smart-city-dream/

[58] WHO (2018) Road Traffic Kills 350,000 Children a Year. WHO Quoted in the Telegraph News.

https://www.telegraph.co.uk/news/2018/05/25/road-traffic-kills-350000-children-ye $\underline{\operatorname{ar} /}$

[59] Rana, U. (2018) Kathmandu Taking to Taxi APPS. Business $360^{\circ}$. https://www.b360nepal.com/feature/kathmandu-taking-to-taxi-apps.html

[60] Sinnott, R. (1984) Virtues of the Haversine. Sky \& Telescope, 68, 158.

[61] Black, W.R. (2010) Sustainable Transportation: Problems and Solutions. The Guilford Press, New York, London. 
[62] State of Delaware (2018) Division of Waste and Hazardous Substances. State of Delaware. http://www.dnrec.delaware.gov/dwhs/info/Pages/OzonePublicTrans.aspx

[63] DART (2018) DART First State. DART: Moving Forward. Delaware Transit Corporation. http://www.dartfirststate.com/

[64] Spector, J. (2018) Study: Electric Buses Already Emit Less Carbon than Diesel Buses, In Any State: And Their Climate Impact Will Decrease as the Grid Gets Cleaner. https://www.greentechmedia.com/articles/read/study-electric-buses-already-emit-le ss-carbon-than-diesel-buses-in-any-stat\#gs.WbGiWwRp

[65] Dhimal, M., Bhusal, C.L. and Bhattarai, L. (2009) Situation Analysis of Environmental Health in Nepal 2009. Technical Report.

https://www.researchgate.net/publication/263051422_Situation_Analysis_of_Enviro nmental_Health_in_Nepal_2009

[66] Tuladhar, B. (2004) Health Impacts of Kathmandu's Air Pollution. PowerPoint PPT Presentation.

https://www.slideserve.com/abra/health-impacts-of-kathmandu-s-air-pollution

[67] ADB (2006) Country Synthesis Report on Urban Air Quality Management-NepalManila. Asian Development Bank.

[68] Vasic, A.-M. and Weilenmann, M. (2006) Comparison of Real-World Emission from Two-Wheelers and Passenger Cars. Environmental Science \& Technology, 40, 149-154.

http://pubs.acs.org/cgi-bin/article.cgi/esthag/2006/40/i01/html/es0481023.html https://doi.org/10.1021/es0481023

[69] Watanatada, T., Harrall, C.G., Paterson, W.D.O., Dhareshwar, A.M., Bhandari, A. and Tsunokawa, K. (1987) The Highway Design and Maintenance Standards Model. World Bank.

[70] Cocchia, A. (2014) Smart and Digital City: A Systematic Literature Review. In: Dameri, R. and Rosenthal-Sabroux, C., Eds., Smart City. Progress in IS, Springer, Cham, 13-43. https://link.springer.com/chapter/10.1007/978-3-319-06160-3_2 https://doi.org/10.1007/978-3-319-06160-3_2

[71] KC, Apil (2019) Plan to Add 2 Million People in the Kathmandu Valley. Setopati. https://setopati.com/opinion/175357

[72] Setopati (2019) Crowded Kathmandu City.

[73] The World Bank (2017) Death in the Air: Air Pollution Costs Money and Lives. http://www.worldbank.org/content/dam/infographics/780xany/2016/sep/WB_costof-pollution-infographic-ENGLISH_for_web.jpg

[74] Shrestha, S. (2016) Dispelling Air Pollution Myths in Kathmandu. International Center for Integrated Mountain Development (ICIMOD). http://www.icimod.org/?q=23487

[75] Kc, A., Wrammert, J., Nelin, V., Ewald, J., Clark, R. and Målqvist, M. (2015) Level of Mortality Risk for Babies Born Preterm or with a Small Weight for Gestation in a Tertiary Hospital of Nepal. BMC Public Health, 15, 877. https://doi.org/10.1186/s12889-015-2232-1

[76] Malley, C.S., Kuylenstierna, J.C., Vallack, H.W., Henze, D.K., Blencowe, H. and Ashmore, M.R. (2017) Preterm Birth Associated with Maternal Fine Particulate Matter Exposure: A Global, Regional and National Assessment. Environment International, 101, 173-182. https://doi.org/10.1016/j.envint.2017.01.023

[77] The Lancet Planetary Health (2017) Government Indifference over Air Pollution Crisis in Delhi. The Lancet Planetary Health, 1, e348. 
https://doi.org/10.1016/S2542-5196(17)30165-1

[78] Cohen, A.J., Brauer, M. and Burnett, R. (2017) Estimates and 25-Year Trends of the Global Burden of Disease Attributable to Ambient Air Pollution: An Analysis of Data from the Global Burden of Diseases Study 2015. The Lancet, 389, 1907-1918. https://doi.org/10.1016/S0140-6736(17)30505-6

[79] Gkiotsalitis, K. and Stathopoulos, A. (2015) A Mobile Application for Real-Time Multimodal Routing Under a Set of Users' Preferences. Journal of Intelligent Transportation Systems, 19, 149-166. https://doi.org/10.1080/15472450.2013.856712

[80] CBS (2013) Central Bureau of Statistics. National Commission of Nepal. Government of Nepal.

[81] Department of Environment (DoEnv) (2017) Air Quality Monitoring. http://pollution.gov.np/

[82] SEI (2007) A Strategic Approach for Air Pollution Reduction in Kathmandu Valley. Stockholm Environment Institute. Policy Brief.

[83] Shindell, D., Kuylenstierna, J.C.I. and Vignati, E. (2012) Simultaneously Mitigating Near-Term Climate Change and Improving Human Health and Food Security. Science, 335, 183-189. https://doi.org/10.1126/science.1210026

[84] MoHP (2014) Ministry of Health and Population. Government of Nepal. Katmandu, Nepal.

[85] Bhandari, G.P., Angdembe, M.R., Dhimal, M., Neupane, S. and Bhusal, C. (2014) State of Non-Communicable Diseases in Nepal. BMC Public Health, 14, 23. https://doi.org/10.1186/1471-2458-14-23

[86] Bhandari, A.A., Gautam, R. and Bhandari, R. (2015) Knowledge and Practice on Prevention of Respiratory Health Problems among Traffic Police in Kathmandu, Nepal. International Scholarly Research Notices, 2015, Article ID: 716257. https://doi.org/10.1155/2015/716257

[87] Bashyal, A., Majumder, A.K. and Khanal, A.N. (2008) Quantification of PM10 Concentration in Occupational Environment of Traffic Police Personnel in Pokhara Sub-Metropolitan City, Nepal. Kathmandu University Journal of Science, Engineering and Technology, 4, 73-80. https://doi.org/10.3126/kuset.v4i1.2886

[88] Shrestha, H.S., Nepal, O., Khanal, K. and Kapoor, B.K. (2015) A Cross-Sectional Study of Lung Functions in Traffic Police Personnel at Work in Kathmandu Valley, Nepal. Annals of Clinical Chemistry and Laboratory Medicine, 1, 42-48. https://doi.org/10.3126/acclm.v1i1.12315 
Appendix A: JavaScript Formula to Calculate Distance

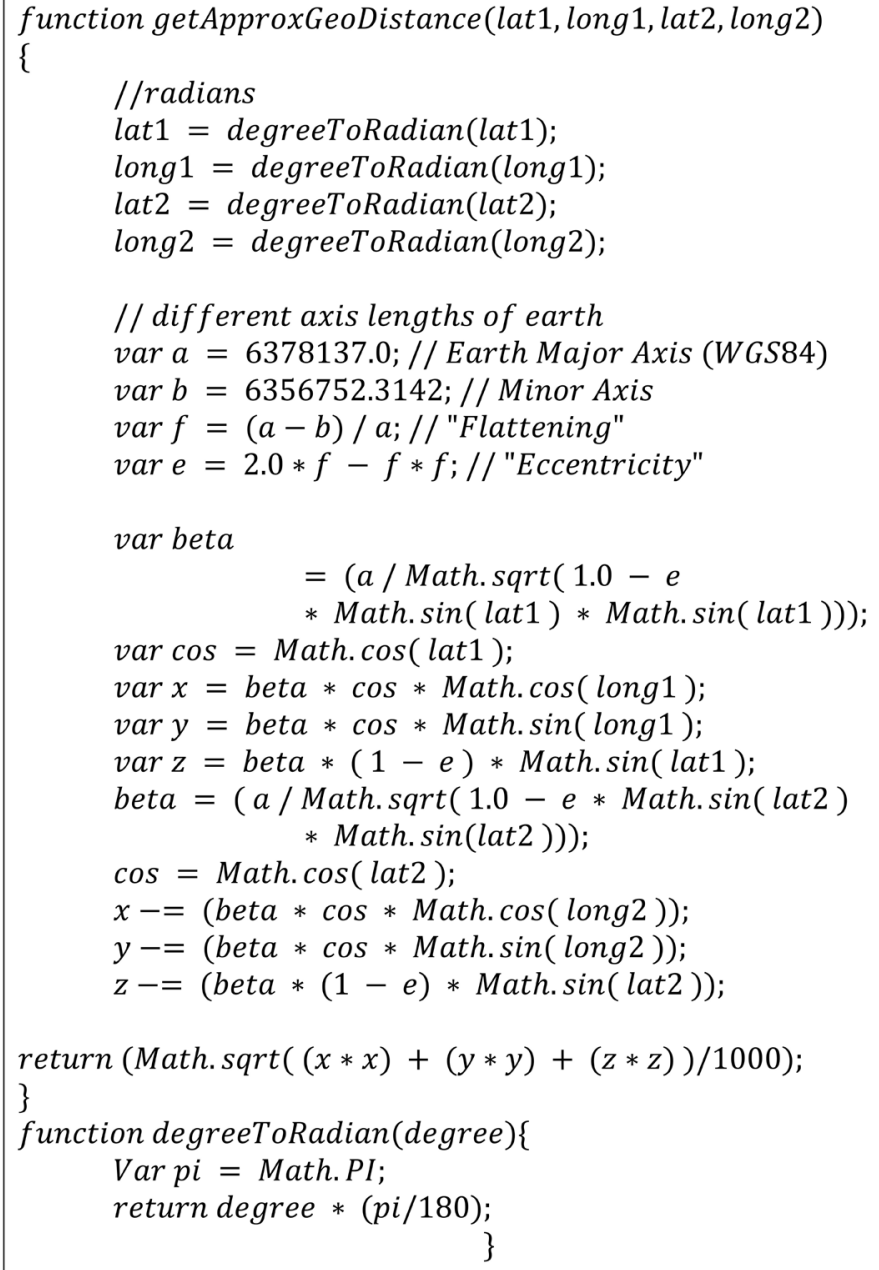

Appendix B: A Comparison of Distances Computed (Using Haversine Formula, Spherical Law of Cosines, and Pythagoras Formula through JAVA Programming) vs. Real (Physically Measured on the Ground) in Kilometers

\begin{tabular}{|c|c|c|c|c|c|}
\hline $\mathrm{SN}$ & LOCATION & LATITUDE & LONGITUDE & DIST (computed) & DIST (real) \\
\hline & Kalanki & 27.693351649 & 85.2818409959 & \multirow[b]{2}{*}{0.30} & \multirow[b]{2}{*}{0.30} \\
\hline & Kalanki-14 & 27.696052503 & 85.2816801066 & & \\
\hline & Yogeshwar Marg & 27.697498804 & 85.2816085934 & \multirow{2}{*}{0.16} & \multirow{2}{*}{0.16} \\
\hline & Panchanan Marg & 27.698943895 & 85.2816289126 & & \\
\hline & Syuchatar & 27.702130267 & 85.2820142711 & \multirow{2}{*}{0.27} & \multirow{2}{*}{0.27} \\
\hline & Chhauni & 27.704560058 & 85.2823199873 & & \\
\hline & SitaPailaChwk & 27.707712283 & 85.2826885979 & \multirow[b]{2}{*}{0.55} & \multirow[b]{2}{*}{0.55} \\
\hline & Sitapaila Marg & 27.712691665 & 85.2832866689 & & \\
\hline & Swoyambu Chwk & 27.716423218 & 85.2837315858 & \multirow[b]{2}{*}{0.31} & \multirow[b]{2}{*}{0.31} \\
\hline & Sano Bhanjyang & 27.718869691 & 85.2853835544 & & \\
\hline
\end{tabular}




\section{Continued}

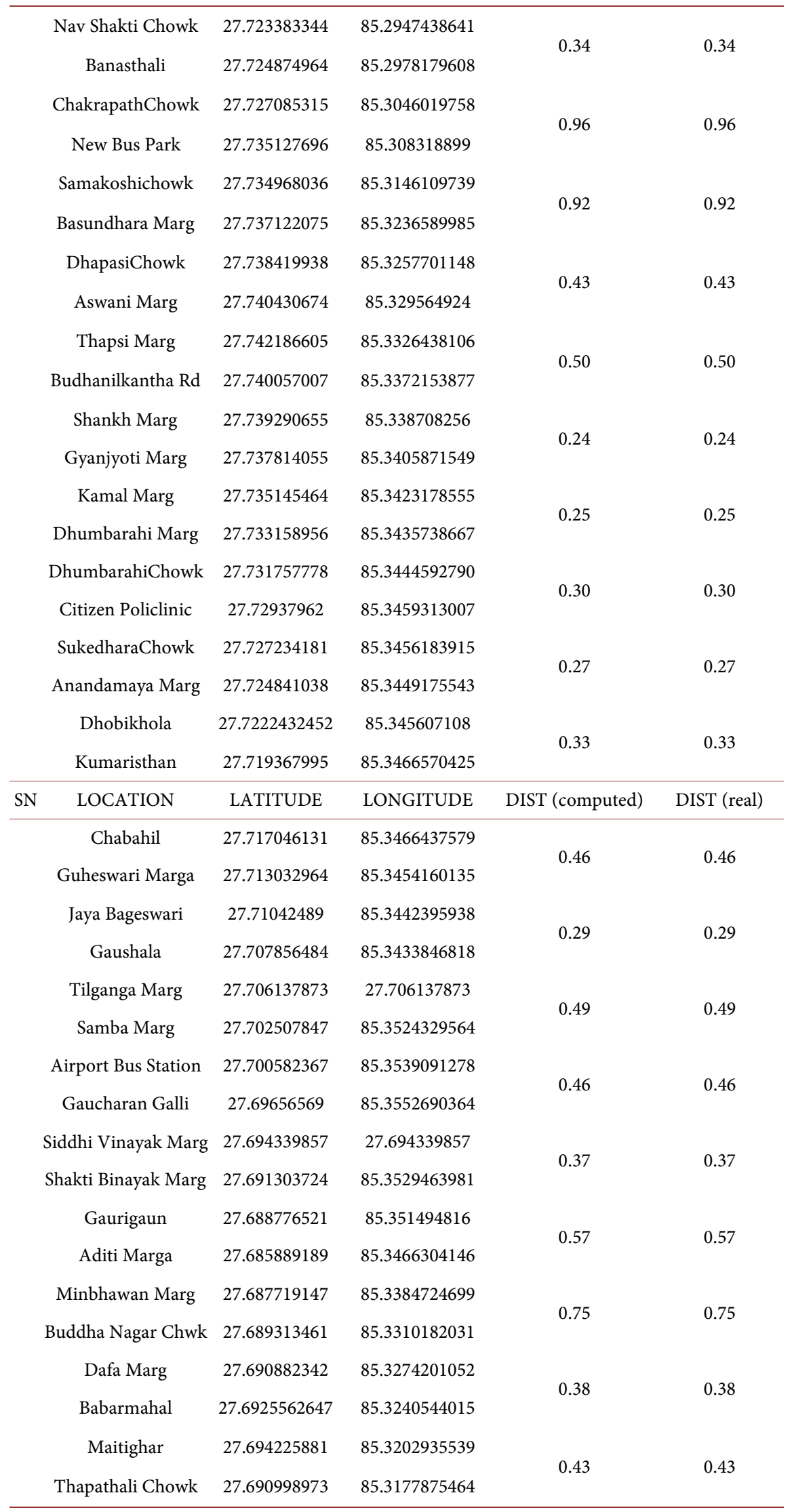




\begin{tabular}{ccccc} 
Continued & & & \\
\hline Tripureshwar Chowk & 27.694123503 & 85.3128085887 & 0.35 & 0.35 \\
Tribhwan Road & 27.695409373 & 85.3094650026 & & \\
Teku Bus Station & 27.696498716 & 85.3063782796 & 0.15 & 0.15 \\
Panchali Marg & 27.697095407 & 85.3050105069 & & \\
Mayapuri Marg & 27.69806414 & 85.3026279302 & & 0.31 \\
Vishwavidyalaya & 27.698460133 & 85.2994990583 & 0.31 & 0.29 \\
Path & 27.697527741 & 85.2964732361 & & \\
Chunni Pakha Galli & 27.696662648 & 85.2936739447 & 0.29 & 0.19 \\
Soltimod & 27.695659087 & 85.2910747019 & & \\
Chunne Bhairab & 27.19 & \\
Marg & & & & \\
Ravi Bhawan & 27.695348677 & 85.2891414863 & &
\end{tabular}

\begin{tabular}{|l|l|l|}
\multicolumn{3}{|c|}{ THIS STATION IS KALANKI } \\
\hline $\begin{array}{l}\text { Bus } \\
\text { Types }\end{array}$ & Arrives & Leaves \\
\hline B1 & $7.25 \mathrm{am}$ & $7.27 \mathrm{am}$ \\
\hline B2 & $8.25 \mathrm{am}$ & $8.27 \mathrm{am}$ \\
\hline B3 & $9.25 \mathrm{am}$ & $9.27 \mathrm{am}$ \\
\hline B4 & $10.25 \mathrm{am}$ & $10.27 \mathrm{am}$ \\
\hline
\end{tabular}

\section{Appendix C: Computing Distances at Global Scale}

Using the Haversine formula, we compared the distances between various locations in different hemispheres of the globe using Google Earth. For example, the ground distances were measured for North America, South America, Russia, Asia using Google Earth, whereas the actual distances were computed using the Haversine formula coded in the Java script.

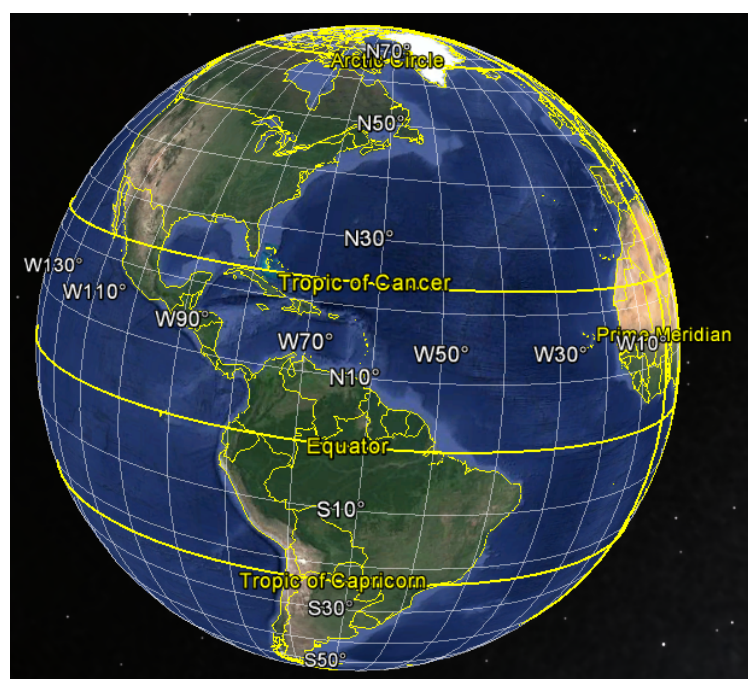

Appendix B. Google Earth 
Results from the direct measurement in Google Earth and values computed using Haversine formula are listed in the table for four quadrants of the globe to justify the universal applications of proposed Transit-Tracker Apps.

\begin{tabular}{ccccccccccccccc}
\hline \multicolumn{1}{c}{ North America } & \multicolumn{4}{c}{ South America } & \multicolumn{2}{c}{ Europe } & \multicolumn{3}{c}{ Russia } & \multicolumn{3}{c}{ Asia } \\
\hline Lat & Long & Dist & Lat & Long & Dist & Lat & Long & Dist & Lat & Long & Dist & Lat & Long & Dist \\
$(\mathrm{DD})$ & $(\mathrm{DD})$ & $(\mathrm{km})$ & $(\mathrm{DD})$ & $(\mathrm{DD})$ & $(\mathrm{km})$ & $(\mathrm{DD})$ & $(\mathrm{DD})$ & $(\mathrm{ml})$ & $(\mathrm{DD})$ & $(\mathrm{DD})$ & $(\mathrm{km})$ & $(\mathrm{DD})$ & $(\mathrm{DD})$ & $(\mathrm{km})$
\end{tabular}

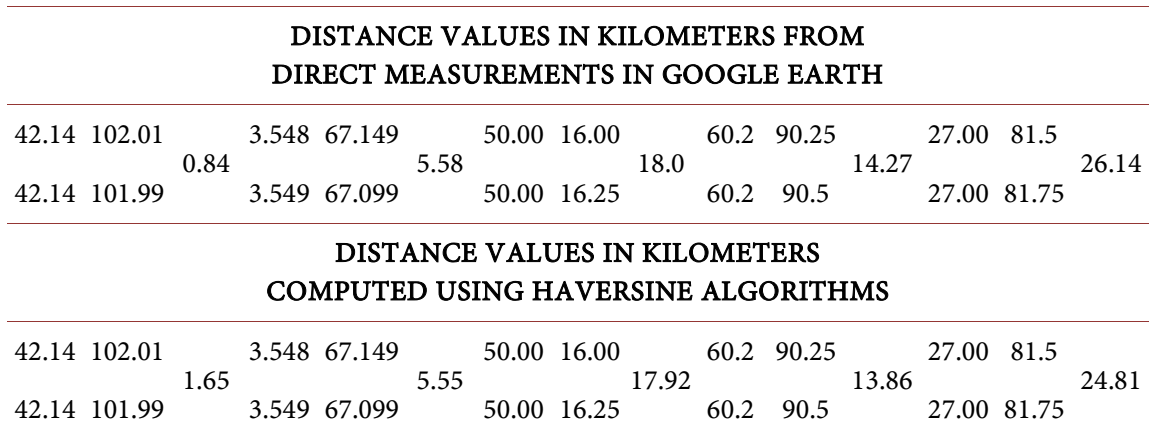

